\title{
Integrating behavioural change and gamified incentive modelling for stimulating water saving
}

\author{
J. Novak ${ }^{1,4}$, M. Melenhorst ${ }^{1}$, I. Micheel ${ }^{1}$, C. Pasini ${ }^{2}$, P. Fraternali ${ }^{2}$, A. E. Rizzoli ${ }^{3}$ \\ European Institute for Participatory Media ${ }^{1}$, Politecnico di Milano ${ }^{2}$, SUPSI - Scuola universitaria \\ professionale della Svizzera italiana ${ }^{3}$, University of Applied Sciences Stralsund ${ }^{4}$ \\ \{j.novak,m.melenhorst, i.micheel\}@eipcm.org, jasminko.novak@hochschule-stralsund.de \\ \{chiara.pasini, piero.fraternali\}@polimi.it, andrea@idsia.ch
}

\begin{abstract}
Stimulating consumers to save water is a challenge and an opportunity for water demand management. Existing ICT systems for behavioural change often do not consider the underlying behavioural determinants in a systematic way. This paper discusses the design of the behavioural change and incentive model combining smart meter data with consumption visualisation and gamified incentive mechanisms to stimulate water saving. We show how the design of such a system can be related to a holistic behavioural change model and how this systematic mapping can inform the design of an integrated incentive model combining different incentive types (virtual, physical, social). The model is implemented in the SmartH2O system and deployed in two pilots. We present the preliminary results for the Swiss pilot, which indicate reduced water consumption, positive user feedback and overall suitability of the designed incentive model.
\end{abstract}

Keywords: Behavioural change, ICT, water saving, incentive modelling, evaluation, real-world pilot

\section{INTRODUCTION}

Enabling new ways of water demand management through ICT has become a major challenge for supporting water efficiency. Different strategies are being explored to address this challenge, ranging from the use of efficient water flow devices and new adaptive pricing policies, to awareness campaigns for sustainable water consumption (Stewart et al., 2010) and the analysis of smart meter data for demand profiling (Cominola et al., 2015). The investigation of new approaches to saving water becomes even more important when considering the significant energy impact of urban water systems and water use in particular, identified by systemic approaches to the modeling and analysis of the water-energy nexus (e.g. Kenway et al., 2015).

Even though large savings can be gained by having consumers buy and install efficient appliances (e.g. water-efficient washing machines), as well as through structural improvements to houses (e.g. installation of a dual water system), these decisions are taken sporadically, have significant financial 
impact, and are difficult to anticipate and influence. Therefore, water utilities are increasingly attempting to influence the habitual behaviour of consumers towards improving water consumption. Water saving through consumer behaviour change has been traditionally addressed with awareness campaigns (Russell \& Fielding, 2010; Seyranian, 2015) and financial incentives (Jorgensen et al., 2009). Recent efforts explore the visualisation of consumption data (Fielding et al., 2013) and gamelike approaches for engaging users in water saving (Wang \& Capiluppi, 2015). Previous studies of awareness campaigns report savings of 5-10\% (e.g. Fielding et al., 2013; Ferraro \& Price, 2013), but also point out a number of issues regarding the sustainability of the achieved behavioural change (e.g. rebound effects). As demonstrated in a large-scale trial by Ferraro \& Price (2013), personalized mailings with appropriate motivational elements (e.g. social norm messages extended with social comparison) can significantly impact the effectiveness of such approaches. Yet, even in such successful trials, the effectiveness of such messages decreased over time.

Determinants and processes of behavioural change for environmentally conscious behaviour have been extensively studied in environmental psychology (e.g. Steg \& Vlek, 2009) and persuasive systems (e.g. Oinas-Kukkonen, 2013), but the influx of these findings into the development of ICTsystems for water saving has been rather limited. In particular, little work has been reported that systematically builds the design of a system and associated incentive model on a theoreticallygrounded model and subsequently validates it in real-world pilots. At the same time, some trials with direct feedback systems have reported water savings of up to 22-27\% (Tiefenbeck et al., 2016, Willis et al., 2010), indicating a large potential of such solutions. However, research in both the water and the energy domain suggests that consumption feedback alone is incapable of inducing a durable change of behaviour (e.g. Schultz et al., 2014; Nachreiner et al., 2015; Fréjus \& Martini, 2016). Similarly, while game-like motivational mechanisms have been successfully applied to influencing user behaviour in different domains (e.g. Sintov et al., 2015), the use of gamification for stimulating water efficiency has been limited and its effect is scarcely documented in scientific literature (Galli et al., 2015).

In this paper we discuss the design of a behavioural change system and of the associated incentive model to induce a sustainable change in water consumption behaviour. The model combines smartmeter based consumption visualisation with gamified incentives to stimulate water saving. We show how the design of such a system can be systematically related to a holistic behavioural change process model to obtain an integrated incentive model combining different types of incentives (virtual, physical, social), adapted to the characteristics of two different pilot types (small-scale, large-scale). We illustrate the model by describing its implementation, deployment and evaluation in a real-world setting. We report on the first results from a small-scale pilot, including impact on water consumption, analysis of platform activity and evaluation with end-users ${ }^{1}$.

1 This paper is a thoroughly revised and extended version of the paper "Behaviour change and incentive modelling for water saving: first experiences from the SmartH2O project" presented at the 8th International 


\section{ICT-ENABLED SYSTEMS FOR RESIDENTIAL WATER SAVING}

While in the energy domain different behavioural change systems have been explored, ICT-based systems that stimulate water efficiency in households are much less investigated (Tiefenbeck, 2014). The progressive adoption of smart meters by water utilities has recently increased the attention for such systems. They visualize consumption data from smart meters to provide consumption feedback to users and raise their awareness about water consumption (e.g. Froelich et al. 2012). In this section we review existing solutions, and outline the contribution of the SmartH2O approach to the knowledge about smart meter-enabled behavioural change systems. One class of systems provides consumption feedback at the level of an individual appliance through a device that is directly attached to it, and is based on the assumption that feedback is most effective when delivered close to the cause of the consumption (Kappel \& Grechenig, 2009). Examples include a "Waterbot" that displays water consumption at the tap in the kitchen (Arroyo et al., 2005), a shower display, which visualizes consumption with coloured LEDs (Kappel \& Grechenig, 2009) or a "Shower Calendar" showing the water consumption of household members on a calendar display in the shower (Laschke et al., 2011). Similarly, the Amphiro on-shower device combines in-shower visualisation with reports viewable on web-based and mobile apps (Tiefenbeck et al., 2014, Tiefenbeck et al., 2016).

Other systems present water consumption data at the level of the household as a whole, through inhome displays, web-based or mobile apps. Such systems feature reporting functionalities for both end-consumers and water utilities. A prominent example is WaterSmart (WaterSmart, 2016), providing a software service for utilities, allowing customers to compare their consumption against neighbours and like-sized homes on the basis of interactive (web, mobile) and paper-based monthly reports, including water saving tips and incentivizing use through rebates (from water suppliers). Their recent pilot in a Californian district reported about 5\% savings per household (Mitchell et al., 2012). Progress on disaggregation algorithms is about to enable a reliable breakdown of water consumption at the appliance level without requiring special sensors (e.g. Nguyen et al., 2013), paving the way for future applications with fine-grained feedback that may further increase water saving rates..

Several on-going EU projects follow similar approaches with some differences. The SmartH2O project (Rizzoli et al, 2014) differentiates itself through daily consumption feedback and integrated gamified incentive model (discussed in this paper), going beyond social comparison and rebates of WaterSmart, and combining visualisation and saving tips with personal, social, virtual and physical rewards (Section 4). Several other efforts are worth noting, even if they have not yet reported details of their approaches or results in scientific literature. The WATERNOMICS project focuses on integrating personalized feedback on water consumption, sensor data and fault detection algorithms, and enabling dashboards and decision support systems for water saving (Clifford et al., 2014; Chambers et al., 2015). The WISDOM project aims at behavioural change through near real-time water consumption feedback on an in-home display and a digital game (Terlet et al., 2016).

Congress on Environmental Modelling and Software Toulouse, France, Sabine Sauvage, José-Miguel SánchezPérez, Andrea Rizzoli (Eds.) http://www.iemss.org/society/index.php/iemss-2016-proceedings 
Even though limited in size, number and duration of trials, evaluations of such systems provide encouraging results on the perceived usefulness of different types of displays and feedback (e.g. Froehlich et al., 2012). Only few evaluations address the impact on water consumption. As an exception, Willis et al. (2010) report a $27 \%$ water consumption reduction after deployment of shower alarms alerting household members when using more than a set amount of water, though in a rather short pilot (two-weeks pilot with 44 households). Most recently, Tiefenback et al. (2016) have reported a $22 \%$ consumption reduction after deployment of on-shower devices with real-time feedback on water and energy consumption in a large-scale field experiment (697 households). These are promising results, even though long-term impact is unclear, due to the limited duration of the trials and possible rebound effects after the interventions. Similarly, while approaches to engaging consumers through game-like motivational mechanisms in non-game contexts (gamification) have been widely explored in the energy domain (e.g. Sintov et al., 2015), the use of gamification in the water sector has been so far limited and scarcely documented in academic literature (Galli et al., 2015). Two recent examples are the aforementioned projects WISDOM, developing a virtual game for water saving (Terlet et al., 2016) and WATERNOMICS, which envisions "games and interactive learning applications" for water saving (Clifford et al., 2014). However, for these projects neither the system implementation, nor an evaluation of the impact on water consumption have been published yet. A systematic grounding in a behavioural change process also hasn't been available.

The addressed systems are often based on the premise that feedback will increase 'awareness', which in turn will induce a change in behaviour. However, recent studies give rise to doubts about this single-focus behavioural change strategy. Smart metered feedback alone has proven to be incapable of inducing a sustainable change in user behaviour (Nachreiner et al., 2015) as effects have shown to decay over time (e.g. Fielding et al., 2013). Moreover, none of the existing systems for stimulating behavioural change for residential water saving derive their design and incentive modelling from a systematic, theoretically informed behavioural change model. In this work, we attempt to support sustainable reduction of water consumption by designing a behavioural change support system that is grounded in the findings from environmental psychology, motivation theory and behavioural change process modelling in a systematic manner.

\section{MODELLING THE BEHAVIOURAL CHANGE PROCESS FOR WATER SAVING}

Our approach aims to stimulate consumers to save water by changing their water consumption habits through their interaction with a behavioural change support system (BCSS), defined as "a sociotechnical information system [...] designed to form, alter or reinforce attitudes, behaviours or an act of complying without using coercion or deception" (Oinas-Kukkonen, 2013, p. 1225). Accordingly, we presume a change in water consumption behaviour to occur when underlying psychological determinants are changed as a result of a combination of different motivational and persuasive strategies. We also model behavioural change as a multistage process (as considered in other domains). 
Accordingly, an effective system for stimulating change in water saving behaviour needs to support all phases of the behavioural change process with an integrated incentive model that combines different incentive types matching the different phases. Research has shown that water consumption behaviour is affected by a multitude of psychological, demographic, climatic and economic factors. However, a behavioural change support system is only capable of influencing the psychological factors (determinants). Generic behavioural change models such as the Theory of Planned Behaviour (TPB, Ajzen, 1991), and water consumption-specific models (e.g. Jorgensen et al., 2009) highlight the determinants that have to be changed to induce a sustainable reduction of water consumption. Applied to water consumption, TPB postulates that beliefs (based on knowledge about water), attitudes (positive or negative evaluation of these beliefs), the subjective norm (perceived social pressure) and behavioural control (the user's belief that s/he can save water) predict whether a user is willing to engage in water saving action (e.g. behavioural intention). Behavioural intention is in turn a predictor of water saving behaviour.

In environmental psychology and behavioural change systems attempts have been made at modelling the behavioural change process. Empirical evidence from evaluations of behavioural change interventions demonstrates the existence of an 'intention-behaviour gap'. This refers to the lack of a relationship between a favourable behavioural intention and the desired behaviour (Bamberg, 2003). Rather than just targeting behaviour determinants, research on effective behavioural change interventions is focused on the behavioural change process. One of the most influential models is the trans-theoretical model for behavioural change (Prochaska \& DiClemente, 1992; Prochaska et al., 2008) developed in the health domain. It models behaviour change through five consecutive phases: from raising awareness ('precontemplation') to eventually creating new habits. While some attempts have been made at modelling behavioural change processes for pro-environmental behaviour in general (e.g. Dahlstrand \& Biel, 1997; Bamberg, 2003), the trans-theoretical model has not yet been applied to the context of household water saving behaviour. In the following, we describe how we have applied and adapted the trans-theoretical model for behavioural change to match the cognitive and motivational processes of water consumption.

\subsection{A multistage process for behavioural change in water consumption}

In doing so, we draw on motivational theory to introduce phase-specific motivational goals (following Ai He, 2010), and issues, thus emphasizing the key role of motivation to drive behavioural change in water consumption. Furthermore, we acknowledge that the behavioural change process is not completely linear, as users can and will relapse to earlier phases. Third, following Noël (1999), we postulate that users progress gradually from one stage to the other, rather than phases being sharply separated. Finally, the pre-action and action phase are merged, arguing that the promoted change of behaviour is relatively small, and involves too little (or no) planning to justify a separate phase (in contrast to behaviours for which the model was originally developed). Table 1 outlines the character of the individual behavioural change phases and the main issues that need to be addressed in each phase in order to stimulate a change in behaviour. 
Table 1.Multi-stage behavioural change process model for water saving (phases, goals, needs).

\begin{tabular}{|l|}
\hline BEHAVIOURAL PHASE \& STATE \\
\hline $\begin{array}{l}\text { Pre-contemplation: } \\
\text { beople are unaware of the need for } \\
\text { change their behaviour }\end{array}$ \\
Motivational goal: \\
"Plant the seed" to acknowledge \\
problematic water consumption behaviour
\end{tabular}

\section{Contemplation:}

People are aware of the need for change, and intend to act; the consideration/identification of appropriate actions and their benefits can result in postponing the behaviour

Motivational goal:

Tip the balance in favour of change

\section{Action:}

People start taking small steps through first actions; need to be prevented from slipping back, requiring continuous reinforcements

Motivational goal:

Reinforce sustainable water consumption

\section{Monitoring:}

people have changed their behaviour; need to be aware of situations that may slip them back to old behaviour

\section{Motivational goal:}

Maintain durable intrinsically motivated behaviour change in water consumption MAIN ISSUES \& NEEDS

- Moving from habits to active thought. Habits are automatic behavioural tendencies that arise as a result of repetition and practice of actions in similar situations (Ouellette \& Wood, 1998). Habits have a strong influence on water consumption behaviour (Jorgensen et al., 2009; Fielding et al., 2012). "Unfreezing" these habits is important (Dahlstrand \& Biel, 1997), since water consumption is predominantly habit-driven and users first need to be motivated to expose themselves to information about their consumption.

- Negative environmental consequences of consuming too much water need to be visualised. Corral-Verdugo et al. (2003) have demonstrated that ecological water beliefs (for example about water being scarce) encourage consumers to save water, while beliefs that claim water to be an unlimited resource have an adverse effect. Interventions can build on this by visualising the relationship between consumption and the impact of that consumption, which is expected to influence underlying beliefs.

- Social norms are unclear or negative. Users are unaware about current descriptive and injunctive social norms, or the current norms are negative. The descriptive norm refers to the prevalence of water saving behaviour, while the injunctive norm refers to the social approval for saving water in a group (Schultz et al., 2014). Social norm strategies have been found effective in various resource conservation studies (Abrahamse \& Steg, 2013).

- Provide factual knowledge about water. In this phase, factual knowledge about water consumption and water behaviour can contribute to more positive attitudes towards saving water. This knowledge deficit approach assumes that behavioural change will incur when a lack of knowledge is filled and a user accepts his own responsibility (Burgess \& Harrison, 1998).

- Emphasize limited impact on hedonic values. Goal framing theory (Lindenberg \& Steg, 2007) suggests that it is important to demonstrate that hedonic values (to e.g. comfort and enjoyment) are not impacted by water saving actions, or that personal gains can be achieved in exchange for only a slight reduction of comfort (e.g. reducing shower time by one minute).

- Increase perceived behavioural control. Survey research has demonstrated that in the Sydney area $31 \%$ of the respondens were unaware of how to save water, suggesting that users should be provided with actionable tips to save water (Randolph \& Troy, 2008).

- Provide positive reinforcements. In line with classical reinforcement theory (Skinner, 1957) positive reinforcements with social, virtual or physical rewards water are expected to keep users engaged with water saving.

- Build new habits. This phase should be focused on internalizing the new behavior into new habits, and that it becomes part of the individual's self. In terms of self-determination theory (Deci \& Ryan, 1985) users need to become intrinsically motivated to save water, without relying on external rewards.

- Keep engagement. In this phase, it is also important to keep users engaged with water consumption. Ai He et al. (2010) - in the context of energy behaviour - suggest to keep a cycle of interest, curiosity, challenge, feedback, and enjoyment. This cycle reflects the incentives provided in SmartH2O. 
Note that the names of the "pre-contemplation" and "contemplation" phases should not be taken literally, but considered as a figure of speech. Users do not necessarily need to explicitly rethink their beliefs and attitudes towards water saving, and are likely to do so rather unconsciously or with little dedicated attention, through exposure to different types of incentives and usage of the system. But in both cases the phases do entail some cognitive attention to issues involved and different user types will vary in the extent of cognitive engagement over the behavioural change process.

Table 1 demonstrates that an effective incentive model for a behavioural change system for water saving should support a wide range of different motivational affordances, i.e. properties of the system that will appeal to different types of motivational needs (Zhang, 2008). An appropriate incentive model should also acknowledge that needs are not stable, but evolve over time, depending on the phase of the behavioural change process. The phases, goals and needs of a multi-stage behavioural change process model for water saving described in the table thus form the basis for a concrete design and implementation of incentive model elements and mechanisms, described in chapter 4.

\subsection{Pragmatic and hedonic affordances}

Before proceeding to the specific incentive model and system design addressing the described behavioural change model, one additional consideration on the affordance requirements for such an incentive and system design is needed. The existing behavioural change models (including the transtheoretical model) tend to focus very strongly on the rationality of human behaviour. However, much research in the field of interactive systems has shown that affective and hedonic aspects (e.g. "joy of use") play an important role both for the acceptance and motivation for use of interactive systems and applications. Given the generally low awareness and involvement of consumers with the topic of water consumption in general, and specifically regarding the need and possibilities to reduce it, such nonrational behavioural drivers can provide important means for motivating the use of a behavioural change support system for saving water.

A well-known perspective considering such motivational affordances differentiates between hedonic and pragmatic aspects that motivate the use of a product or system (Hassenzahl 2004; 2008). Pragmatic aspects relate to the user's need to fulfil a specific task or achieve a goal, while hedonic aspects (joy of use) are related to the user's need for stimulation, novelty and challenge, or expression of identity. Approaches taking up this perspective tend to divide computer systems between "utilitarian systems" emphasizing the functional (task-related) aspects, and "hedonic systems" focusing on the user experience, i.e. the user's self-fulfilment in using the system (Van der Heijden, 2004). In utilitarian systems users are motivated to use the system with the expectation of a reward or benefit external to their interaction with the system, while hedonic systems support activities in which users are intrinsically motivated by the enjoyment of the interaction with the system as such.

Hedonic motivations include the stimulation of users by system novelty or by enabling them to communicate important personal values to others through displaying their usage of the system 
(Hassenzahl, 2004, p. 322). Accordingly, the primary design objective of utilitarian systems is their effectiveness in accomplishing a specific task, whereas for hedonic systems it is the user's enjoyment, leading to continued use of the system (ibid). Measuring pragmatic and hedonic qualities of a system is thus a way to assess how well the system design fits the respective purpose, and specific questionnaire designs have been demonstrated to measure such qualities in a reliable way (Hassenzahl 2004; 2008). Thus, consciously designing a system for specific kinds of pragmatic and/or hedonic qualities can provide important motivational affordances for system usage (Zhang, 2008).

The distinction between hedonic and utilitarian systems has been frequently presented as a dichotomy in the literature, but some studies have pointed out that a class of systems exists that inherently combine the two aspects (e.g. Novak \& Schmidt, 2009). We argue that such a more balanced view should also be applied to the design of behavioural change support systems for water saving. Achieving water saving is a task that needs to be supported with appropriate functional means to achieve it (e.g. water saving tips). To motivate prolonged system usage, using the system should provide sources of "enjoyment" for the user. Accordingly, both the system design and the elements of the incentive model to motivate system usage should consider both pragmatic and hedonic aspects.

\section{DESIGN OF THE INCENTIVE MODEL FOR WATER SAVING IN THE SMARTH2O SYSTEM}

The incentive model has been constructed within the setting of the SmartH2O project that has been set up to address real-world challenges of utilities and municipalities to reduce water demand as part of their long-term strategy regarding infrastructure planning and environmental responsibility. The developed incentive model and the design of the behavioural change system thus provide points of departure that are applicable beyond the context of this specific project. The developed incentive model fuses insights from three different sources (Figure 1): a literature analysis of the state-of-the-art, an assessment of user needs ('user pull'), and alignment with both technical ambitions to leverage the potential of smart metering and technical feasibility ('technology push').

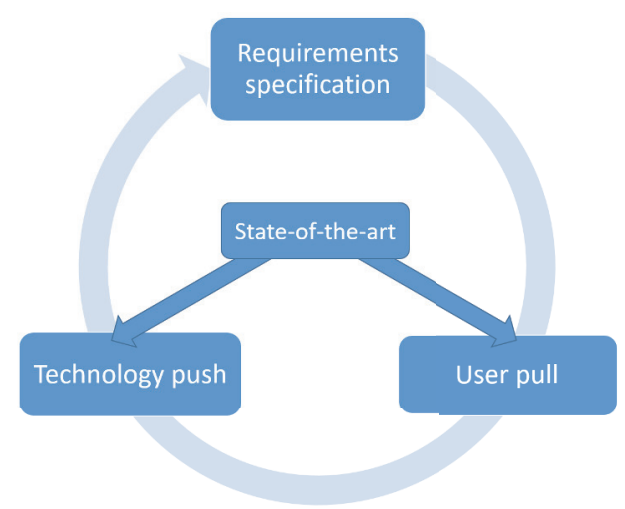

Figure 1. Design process combining "user pull" and "technology push".

In the user pull phase, user needs are elicited and tentative requirements are iteratively evaluated with stakeholders. In the technology push phase, technological (project) objectives and scientific challenges with respect to environmental modelling and smart meter-based feedback systems are aligned with technological and practical constraints. This ultimately leads to the specification of 
technical use cases and associated functional requirements. The resulting incentive model for applications to stimulate water saving in households employs multiple motivational mechanisms orchestrated to reinforce each other and to cover all phases of the behavioural change process. These include interactive consumption visualisations, water saving tips, goal setting, different types of gamified incentives (personal, social, virtual, physical) and a hybrid physical-digital card game. The roles of these elements across the behavioural change process phases are outlined in Table 2.

Table 2. Incentive model elements with respect to behavioural change phases.

\begin{tabular}{|c|c|c|c|c|}
\hline Functionalities & Pre-contemplation & Contemplation & Action & Monitoring \\
\hline \multirow[t]{2}{*}{$\begin{array}{l}\text { Interactive } \\
\text { visualisation } \\
\text { and monitoring } \\
\text { of water } \\
\text { consumption }\end{array}$} & $\begin{array}{l}\text { Mechanisms } \\
\text { - Raise awareness through water } \\
\text { consumption feedback } \\
\text { - Enable social comparison with } \\
\text { neighbourhood averages } \\
\text { - Highlight negative consequences } \\
\text { by visualising longer-term effects } \\
\text { - Unfreeze habits by increasing } \\
\text { knowledge on water consumption }\end{array}$ & $\begin{array}{l}\text { Mechanisms } \\
\text { - Water consumption } \\
\text { feedback makes } \\
\text { users more favour- } \\
\text { able towards saving } \\
\text { water } \\
\text { - Green and red flash } \\
\text { lights indicate the } \\
\text { right thing to do }\end{array}$ & $\begin{array}{l}\text { Mechanisms } \\
\text { statistics } \\
\text { demonstrate } \\
\text { necessity to start } \\
\text { saving water now }\end{array}$ & $\begin{array}{l}\text { Mechanisms } \\
\text { - Water } \\
\text { consumption } \\
\text { statistics } \\
\text { demonstrate } \\
\text { necessity for } \\
\text { actions to save } \\
\text { water }\end{array}$ \\
\hline & \multicolumn{4}{|c|}{$\begin{array}{l}\text { Motivational affordances } \\
\text { - Visualisations designed for hedonic quality increase engagement with saving water } \\
\text { - Daily feedback continuously raises attention to water consumption during behavioural change process }\end{array}$} \\
\hline \multirow[t]{2}{*}{ Water saving tips } & $\begin{array}{l}\text { Mechanisms } \\
\text { - Tips increase user's responsibility: } \\
\text { what can the user do to save water? }\end{array}$ & & $\begin{array}{l}\text { Mechanisms } \\
\text { - Actionable tips to sa } \\
\text { sense of control over }\end{array}$ & $\begin{array}{l}\text { e water give a } \\
\text { wn consumption }\end{array}$ \\
\hline & \multicolumn{4}{|c|}{$\begin{array}{l}\text { Motivational affordances } \\
\text { - Points are awarded for viewing tips and videos (see virtual/social/physical rewards) }\end{array}$} \\
\hline $\begin{array}{l}\text { Virtual, social, and } \\
\text { physical rewards }\end{array}$ & \multicolumn{4}{|c|}{$\begin{array}{l}\text { Motivational affordances } \\
\text { - Gamified elements continuously reinforce user engagement with water saving } \\
\text { - Points, badges and being on the leaderboard offer a sense of achievement, } \\
\text { - Leaderboard enables social comparison with other users, and appeals to users' need for competition } \\
\text { - Physical rewards engage users who are less appealed by game elements }\end{array}$} \\
\hline \multirow[t]{2}{*}{$\begin{array}{l}\text { Setting water } \\
\text { consumption } \\
\text { goals }\end{array}$} & & & \multicolumn{2}{|c|}{$\begin{array}{l}\text { Mechanisms } \\
\text { - Self-set goals create commitment to } \\
\text { saving water / repeatedly achieving } \\
\text { saving targets fosters new habits }\end{array}$} \\
\hline & & & \multicolumn{2}{|c|}{$\begin{array}{l}\text { Motivational affordances } \\
\text { - Points for setting and achieving goals }\end{array}$} \\
\hline \multirow[t]{2}{*}{$\begin{array}{l}\text { Hybrid digital and } \\
\text { card games } \\
\text { (Drop! The } \\
\text { question) }\end{array}$} & $\begin{array}{l}\text { Mechanisms } \\
\text { - Quiz questions raise awareness, } \\
\text { increase knowledge and thinking } \\
\text { about water within the household }\end{array}$ & $\begin{array}{l}\text { Mechanisms } \\
\text { - Game roles establish } \\
\text { the norm: saving water } \\
\text { is right thing to do. }\end{array}$ & $\begin{array}{l}\text { Mechanisms } \\
\text { - Saving tips give a } \\
\text { sense of control of } \\
\text { their consumption }\end{array}$ & \\
\hline & \multicolumn{4}{|c|}{$\begin{array}{l}\text { Motivational affordances } \\
\text { - Fun-of-use of the game increases household engagement with water saving } \\
\text { - Game enables social learning between family members and motivates to use the SmartH2O portal }\end{array}$} \\
\hline
\end{tabular}

The water consumption visualisations are designed to raise awareness about water consumption and point out the consequences of the current behaviour in early phases of the behavioural change process. In later phases, continuous feedback helps to keep the user's attention. Water saving tips 
aim at facilitating the transformation of favourable attitudes towards water saving into concrete actions. Gamified virtual, social and physical rewards can motivate users by appealing to basic human needs, such as a sense of achievement and competitive comparison. Rewards help to reinforce positive water saving behaviour. Goal setting provides users with a sense of achievement, increases commitment and helps establish new habits. Finally, the hybrid physical-digital card game extends the reach to the whole household, by first creating awareness in the whole family, subsequently giving tips to save water and then using the game playing to nudge the family into using the resulting application.

\subsection{Interactive visualisation and monitoring of water consumption}

The use of visualisation as a means of stimulating behaviour change for natural resource conservation (e.g. water and energy) has been investigated by different approaches (e.g. Froehlich at al., 2012). Its effect on user behaviour can be attributed to consumption visualisations influencing underlying beliefs and attitudes towards water saving (Fielding et al., 2012) and their impact in the different behavioural change phases (Table 1, Table 2). Consumption feedback has the potential of appealing to the user's need for achievement in the sense that a well-visualized decrease of water consumption levels feeds the user's feeling of accomplishment (e.g. need achievement theory, Atkinson; 1960), as well as the user's feeling of autonomy (self-determination theory, Deci \& Ryan, 1985). However, the positive effect of feedback should not be taken for granted, as rebound effects have been found (e.g. Fielding et al., 2013 for water; Abrahamse et al., 2005 for energy) and problems with user engagement have been diagnosed too (Buchanan et al., 2015).

While different approaches have employed different types of visualisations with varying success (Micheel et al., 2015) in both the water and the energy domain, a systematic approach incorporating the lessons learned has not yet been reported. In Micheel et al. (2015) these lessons have been synthesised into design guidelines for consumption visualisation for behavioural change in both domains. Table 3 summarizes the guidelines from this synthesis that guided our visualization design.

Table 3. Guidelines for consumption visualisation for behavioural change (Micheel et al., 2015).

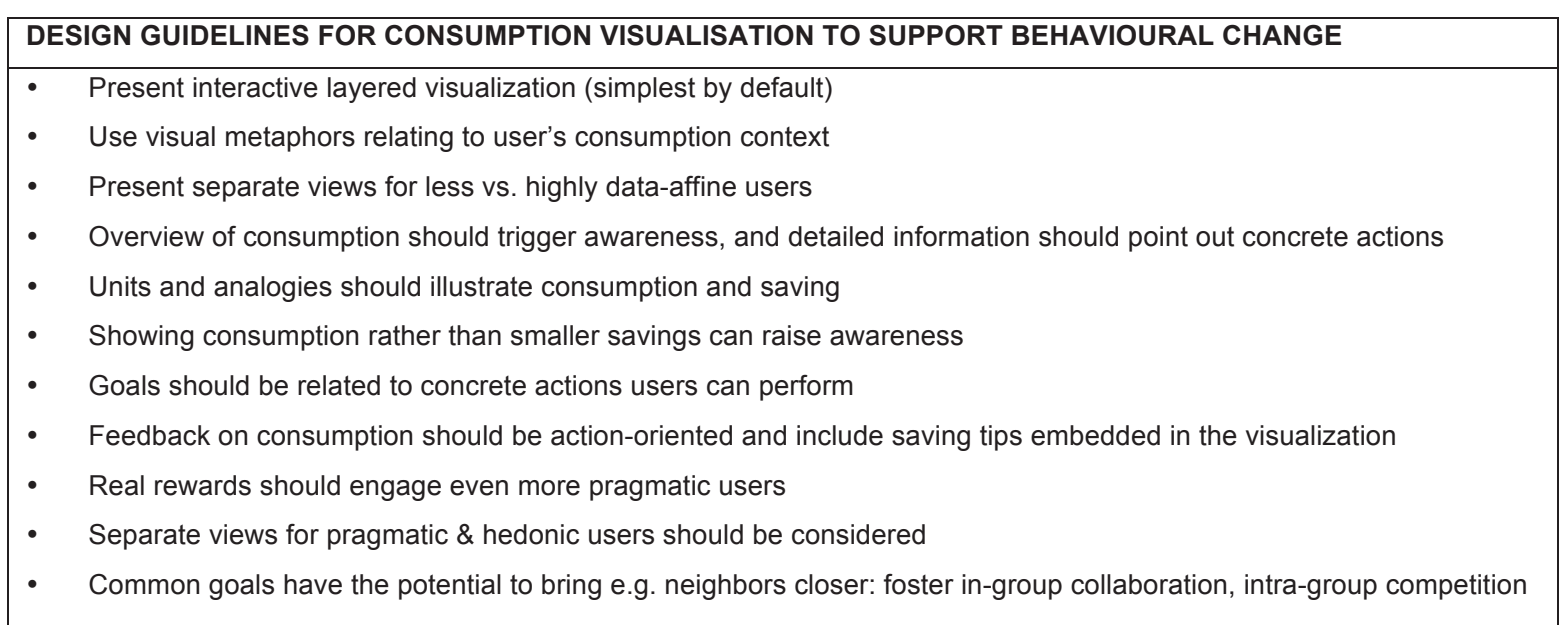

In the resulting incentive model, water consumption visualisation has two elements (Figure 2). The first one visualizes the user's water consumption as bar charts (Figure 2,a), over different time spans. It includes the average consumption level of their neighbourhood (social comparison). In a first version 
the second element was an overview visualisation showing daily and monthly consumption compared to one's average in a meter metaphor (Figure 2,b). In a second version, this visualisation was replaced with a water pipe metaphor (Figure 2,c) to support more immediate cognitive mapping to the water topic and reinforce water awareness (following guidelines from Micheel et al., 2015).

Accordingly, this visualisation displays user's water consumption levels in a pipe filled with water, accompanied with goal setting and monitoring functions and a visualisation of consumption effects (Figure 2,c). The historical baseline value depicted with a dashed line provides a point of reference for the consumed quantity (historical comparison). Users are encouraged to save water with the display of water consumption levels that are $5 \%, 10 \%$ and $15 \%$ below the baseline consumption. Benchmarks for comparison are important, as they allow users to judge if their consumption is "normal", excessive or economical (Froehlich, 2012), attributing meaning to their behaviour. The green or red light on top of the water pipe also gives an injunctive normative message. If consumption is lower than the historical base value, the light is green and a positive reinforcement message is displayed. Normbased strategies have been found to be effective for inducing behavioural change in water consumption (e.g. Katz et al., 2016; Seyranian et al. 2015). If consumption is higher than the historical value, a red light and a warning message are displayed. The effect of current consumption extrapolated over a year is also displayed as a number of swimming pools filled with water (Figure 2, c). This can raise awareness about the negative consequences of the current behaviour, which is considered important to support the pre-contemplation phase (Bamberg, 2003).

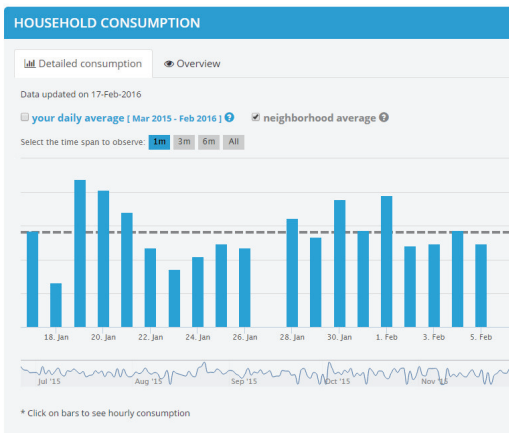

a)

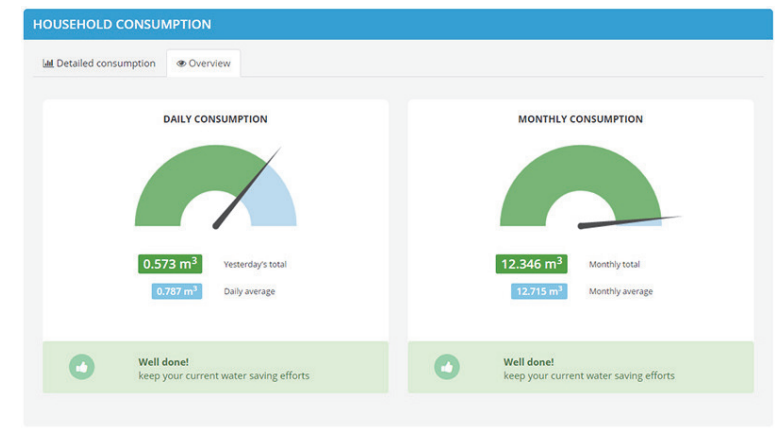

b)

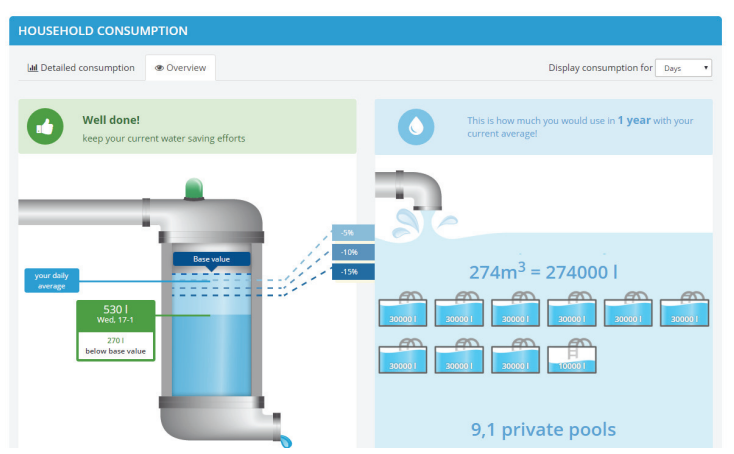

c)

Figure 2. Interactive water consumption visualisation and monitoring: a) detailed consumption, b) consumption overview v1 (meter metaphor), c) consumption overview v2 (pipe metaphor). 


\subsection{Reinforcements through virtual, physical and social rewards}

The incentive model exploits gamification to increase awareness and engagement with water efficiency. Studies in the structurally similar domain of energy consumption have shown that consumers' engagement with energy feedback is problematic, and possibly dissipating over time (Buchanan et al., 2015). Gamification, i.e. the use of game design elements in non-game contexts (Deterding et al., 2011), can be used to increase engagement throughout the behavioural change process. Gamification appeals to the basic human needs of competition, achievement, social status, and the need to collect (Basic desires theory; Reiss, $2000^{2}$ ). Little attention has so far been paid to the potential of gamification to support behavioural change for water saving. However, studies in the energy field have shown that not only real prize-like rewards, but also gamified social interaction can foster behaviour change through competitive and cooperative approaches (see overview in Micheel et al., 2015). Gamification is also expected to increase the hedonic quality of a product (e.g. Hassenzahl, $2004 ; 2008)$, offering a stimulating and fun experience to the users. In their research the authors have found that these hedonic attributes are strongly related to its quality, as perceived by the users.

The SmartH2O incentive model awards points and badges for specific user actions, while a leaderboard is used to prompt competition and comparison between users (see Figure 3). It is designed to appeal to both intrinsic and extrinsic motivations. Intrinsic motivation is stimulated by allowing users to show their ability to themselves and to others (need achievement theory ${ }^{3}$, Atkinson \& Litwin, 1960). Points (virtual rewards) are given and displayed for various actions. They can be collected in four different thematic areas: water saving (reducing consumption), water efficiency education (e.g. reading tips, watching videos), profiling (providing details about e.g. the household composition) and participation (e.g. posting results to social networks). Achievement is recognized by awarding thematic badges (e.g. when users reach the first 1000 points in the water saving area, they get the "smart saver"-badge). Table 4 outlines the badges per thematic area.

Table 4. Badge levels per thematic area.

\begin{tabular}{|l|c|c|c|c|}
\hline Badges & Badge icon & Level 1 & Level 2 & Level 3 \\
\hline \hline Water saving & 0 & Beginner saver & Advanced saver & Super saver \\
\hline \hline Water saving insights & 0 & Smart saver & Expert saver & Guru saver \\
\hline \hline Profiling & & Beginner profiler & Advanced profiler & Super profiler \\
\hline \hline Participation & $\ddots$ & Engager & Influencer & - \\
\hline
\end{tabular}

\footnotetext{
2 Basic desires theory identifies sixteen basic desires that guide a large part of human behaviour (Reiss, 2000). It states that these desires motivate people's actions and define their personalities (ibid.). The desires are the need for approval, learning, food, raising children, loyalty to traditional values, social justice, independence, organized environments, physical activity, power, romance saving and collecting, social contact, social status, safety, and competition.

${ }^{3}$ Need achievement theory states that achieving success and avoiding failure are separate motives that guide human behaviour in order to demonstrate to oneself or to others high rather than low ability (Atkinson, 1960). People highly motivated to succeed prefer tasks of intermediate difficulty but if the motive to avoid failure is stronger, people tend to prefer either very simple or very difficult tasks (Atkinson, 1960; Richter et al., 2015).
} 
Both badges and the weekly leaderboard afford social comparison, a recognised driver for behavioural change. Furthermore, appealing to the basic desire for competition (Reiss, 2000), competition between users is encouraged by displaying top achievers on weekly and overall leader-boards. Extrinsic motivation is encouraged with physical rewards, by engaging users in a challenge that can be organized in two versions, matching different pilot scales and business constraints.

In the first type of challenge, physical rewards are awarded when a user has collected a certain number of points. In the second type of challenge, rewards are allocated by means of a periodic competition (e.g. top users on a weekly leaderboard are designated as winners of the weekly prize). The rewards awarded by achieving a set number of points consist of the Drop! card game and water saving gadgets (e.g. efficient shower heads), as shown in Table 5 (in our case this type of rewards has been applied for a small-scale pilot; see Chapter 6).

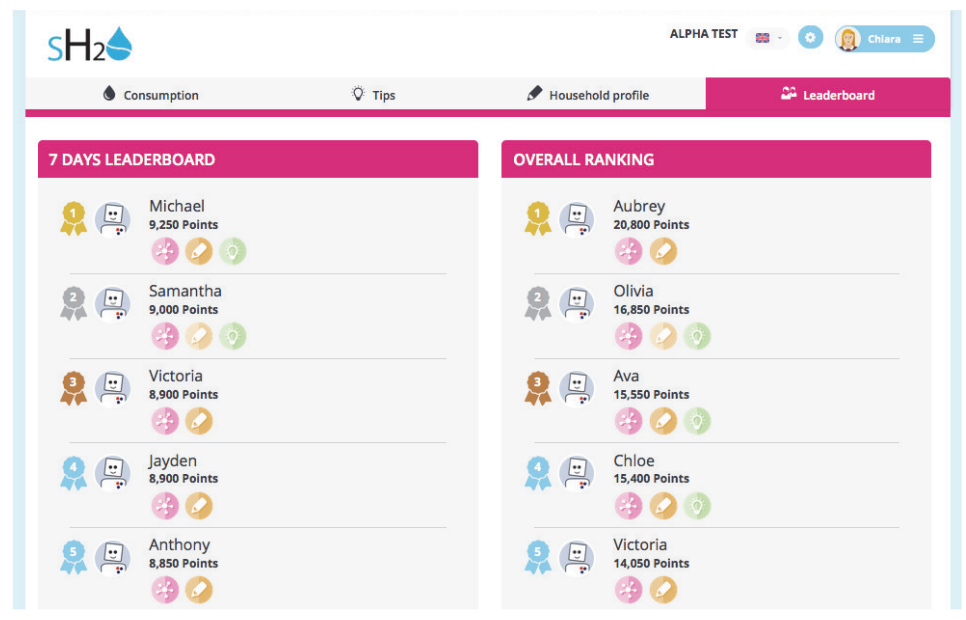

Figure 3. Weekly and overall leaderboard.

The set-up with bigger and smaller rewards affords different patterns of behaviour. New users may claim a smaller reward right after collecting a small number of points, which rewards their initial engagement with the system and at the same time gives them an educational game, purposely designed to increase their attitude towards saving. Other users who are driven by the need for collection (Reiss, 2000) can continue to collect points until they qualify for more valuable rewards that are also more difficult to achieve,.

Table 5. Rewards available and points needed for redemption in a small-scale pilot.

\begin{tabular}{|l|r|}
\hline Reward & Points \\
\hline $\begin{array}{l}\text { Drop! Board game. Drop! Board game for all ages. Learn more about water consumption with Lily } \\
\text { and the Monster. }\end{array}$ & 50 \\
\hline Push. When installed, pushing the "Push"-button reduces tap water consumption by 50\%. & 21000 \\
\hline Cascade. Cascade permanently reduces tap water consumption by 50\%. & 21000 \\
\hline $\begin{array}{l}\text { Ecobooster Showerhead. The Ecobooster switches the water consumption of your shower to eco- } \\
\text { mode with a simple button. }\end{array}$ & 25000 \\
\hline $\begin{array}{l}\text { Shower LED. This LED light shower sets the mood with seven different colours that change } \\
\text { automatically and independently of the water temperature. No battery necessary. }\end{array}$ & 60000 \\
\hline $\begin{array}{l}\text { Amphiro b1. The Amphiro b1 gives real-time consumption feedback in the shower on the used water } \\
\text { and energy and the current temperature. It sends the information via Bluetooth to users mobile device. }\end{array}$ & 80000 \\
\hline
\end{tabular}


Point-based achievement rewards are suitable for smaller scale pilots only, because all users could in principle attain all rewards, which induces costs that may quickly get prohibitively high in large-scale deployments. For this reason the alternative competition-based reward scheme is also supported. Initial engagement is encouraged by granting a reward (the Drop! card game) after a small amount of initial user activity. To encourage ongoing engagement, additional rewards (e.g. museum tickets) can be assigned on a periodic basis(e.g. weekly) only to the top user on the periodic leaderboard. Finally, a number of "big" prizes (such as tablets) can be awarded at the end of the competition timeframe. Finally, a small number of "big" prizes (high-end tablets) are awarded at the trial's end. This periodic competition scheme safeguards economic constraints on large-scale pilots, because it puts a cap on the maximum number of rewards that must be available. The mix of periodic and final rewards encourages users to remain continuously active in both the short and the longer term. This acknowledges the reinforcement theory (Skinner, 1957; Richter et al., 2015) ${ }^{4}$, which demonstrated the need for continuous reinforcement to maintain the change in behaviour until new habits have been formed, as a final result of a user's intrinsic motivation (Deci \& Ryan, 1985).

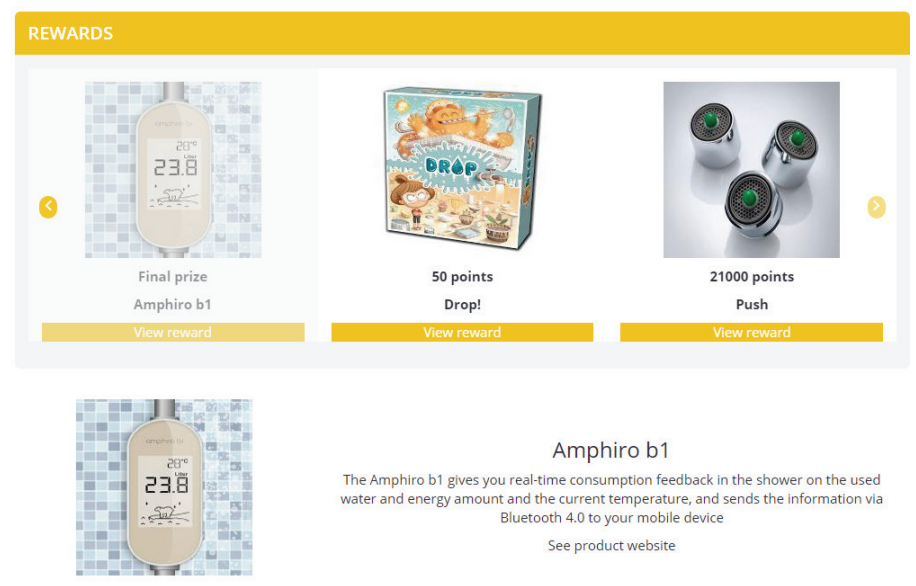

Figure 4. Claiming physical rewards in the small-scale pilot.

\subsection{Setting water saving goals}

Even though self-setting goals have shown promising results in energy consumption (e.g. Abrahamse, 2015), this mechanism has received less attention in the water domain. Goal setting provides users with a sense of achievement (goal-setting theory, Ling et al., 2005) ${ }^{5}$, and increases commitment towards saving water, while supporting the formation of new habits. In the SmartH2O application,

\footnotetext{
4 According to Skinner (1957), an individual's behaviour with negative consequences tends not to be repeated as people generally seek out and remember information that provides cognitive support for their pre-existing attitudes and beliefs. Skinner noted that continuous reinforcement establishes desired behaviours quicker than partial reinforcement. However, once the continuous reinforcement is removed, the desired behaviours extinguish fast (Richter et al., 2015). The reinforcement theory explains the motivation to perform actions or behaviours that lead to extrinsic rewards.

5 Goal Setting Theory claims that difficult, specific, context-appropriate, and immediate rather than long-term goals, are drivers of high achievements (Ling et al., 2005). A goal is perceived as what the individual is trying to accomplish by directing attention, assembling effort, increasing persistence and belief in ability to complete a task. Efficient goals are proximate in time, moderately difficult, and specific, with an objective definition that is understandable for the individual (Locke et al., 1981).
} 
users can set weekly and monthly water saving goals at three different levels (5\%. $10 \%$ and $15 \%$ reduction). More points are awarded for achieving self-established goals than for achieving the same reduction level without setting the goal. The more ambitious the goal, the more points a user receives. The impact of a goal is visualized by showing how many bathtubs filled with water one would save if the goal is achieved for one year's time (Figure 5).
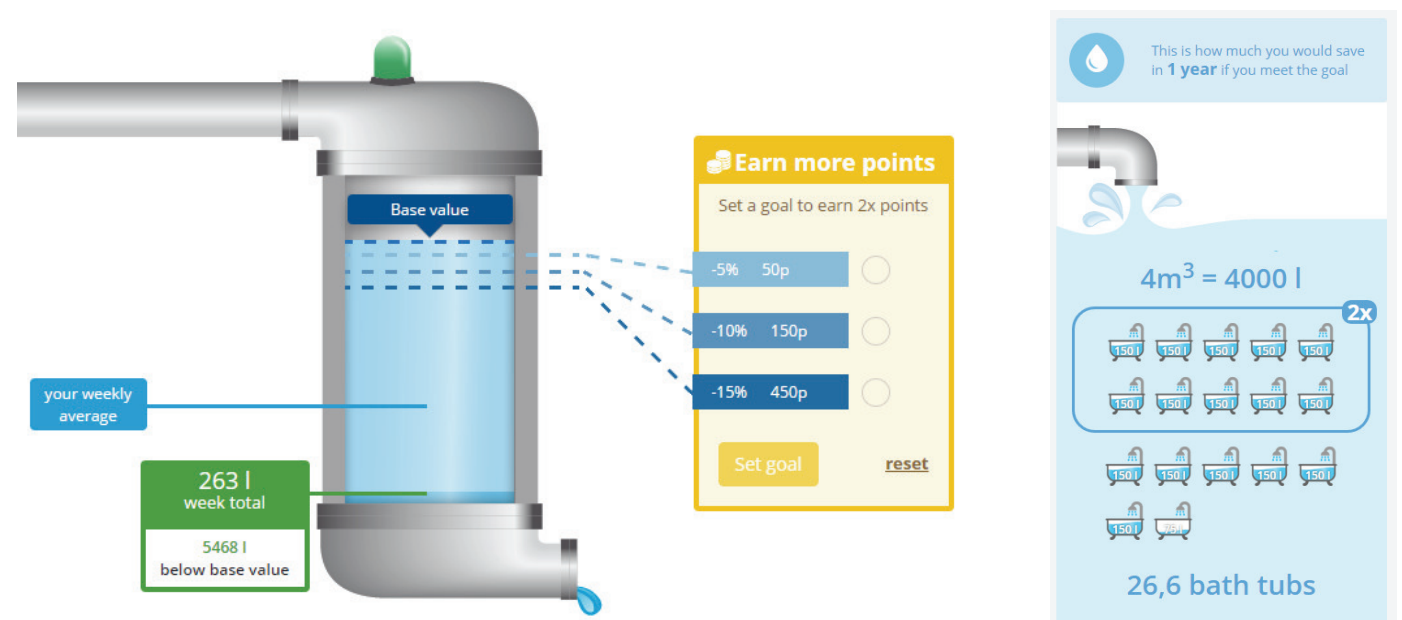

Figure 5. Earning points by setting and achieving goals.

Self-set goals are expected to create commitment towards saving water. Not achieving these self-set goals causes cognitive dissonance, whereas achievement of the goals is expected to strengthen the user's hedonic (e.g. pleasure), normative (how one is expected to behave), and gain goals (e.g. saving money on the water bill), in terms of the goal framing theory (Lindenberg and Steg, 2007).

Demonstrating how much one can save can result in increased awareness of the consequences, a higher self-efficacy (Bandura, 1977) and a higher responsibility. Achievement of the goals motivates users intrinsically, as it strengthens their feeling of competence and mastery (Deci \& Ryan, 1985). Finally, goal-setting is linked to the gamification incentives: achieving goals yields points, which results in social recognition when the user gets visible on either the weekly or global leaderboard. These social rewards are expected to further motivate the user and increase intrinsic motivation (Deci \& Ryan, 1985). Intrinsic motivation supports the eventual formation of new habits (Dahlstrand \& Biel, 1997), which contributes to the sustainability of the behavioural change.

\subsection{Water saving tips}

A significant share of consumers is unaware of how they can save water (Randolph \& Troy, 2008). It is thus not surprising that providing water saving tips can induce behaviour change. Fielding et al. (2013) have demonstrated that showing users how to save water indeed leads to lower levels of water consumption. Both brief textual tips (see Figure 6) and engaging educational videos are available, that concretely show how water can be saved. 


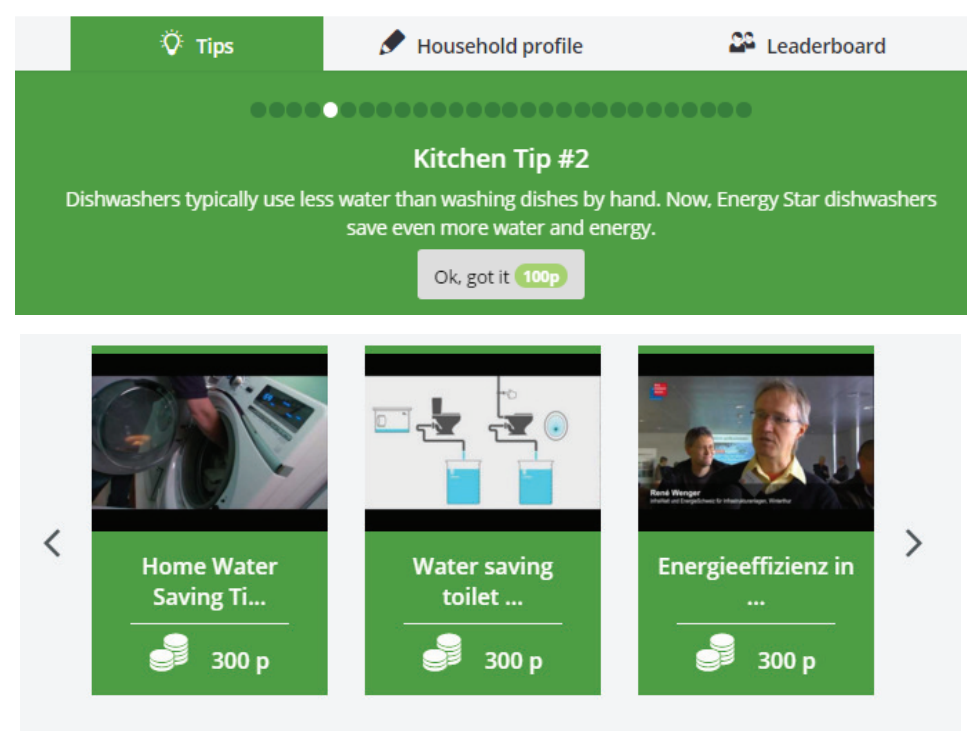

Figure 6. Earning points by reading water saving tips and watching videos about water saving.

The theory of planned behaviour (Ajzen, 1991) and the self-efficacy theory (Bandura, 1977) ${ }^{6}$ suggest that the user's self-confidence about performing the desired behaviour affects the likelihood of actually starting to save water. Water saving tips are included in the incentive model to increase the user's confidence in his ability to save water. The tips are instrumental to the pre-contemplation phase when users need to be persuaded that they can do so and the action phase when users must get support to put their positive attitudes into practice.

\subsection{Incentivizing water saving by playing a hybrid online and card game}

A hybrid physical-digital card game 'Drop! The question' (Fraternali et al., 2015) was designed to raise water saving awareness and encourage social learning within households. This is important, not only as the composition of the household is a strong predictor of water consumption (Jorgensen et al., 2009), but also to influence the water conservation culture of the household (Fielding et al., 2012).

The game is a hybrid card and mobile game for 3-6 players. The game features Lilly, a little girl who wants to save water, and a clumsy monster who keeps spilling water.

Each Lily card displays one action that leads to water saving. The game mechanics is a variant of the popular black-jack card game. Users take turns in drawing cards and they can be challenged on the maximum number of "good" cards they will draw before hitting a monster card. At the end of the game, the player gets points for the Lily cards she has collected. Conversely, monster cards points are deducted, but this can be recovered by correctly answering questions in a mobile app launched by scanning the QR-code that appears on the monster card (Figure 7).

6 Self-efficacy theory (Bandura, 1977) focuses on the individual's belief in his/her ability to succeed in specific situations. Self-efficacy can enhance or impede motivation. People with high self-efficacy choose to perform more challenging tasks, investing more effort and persisting; and when failure occurs they recover more quickly and maintain the commitment to their goals (Schwarzer et al., 1997; Richter et al., 2015). 

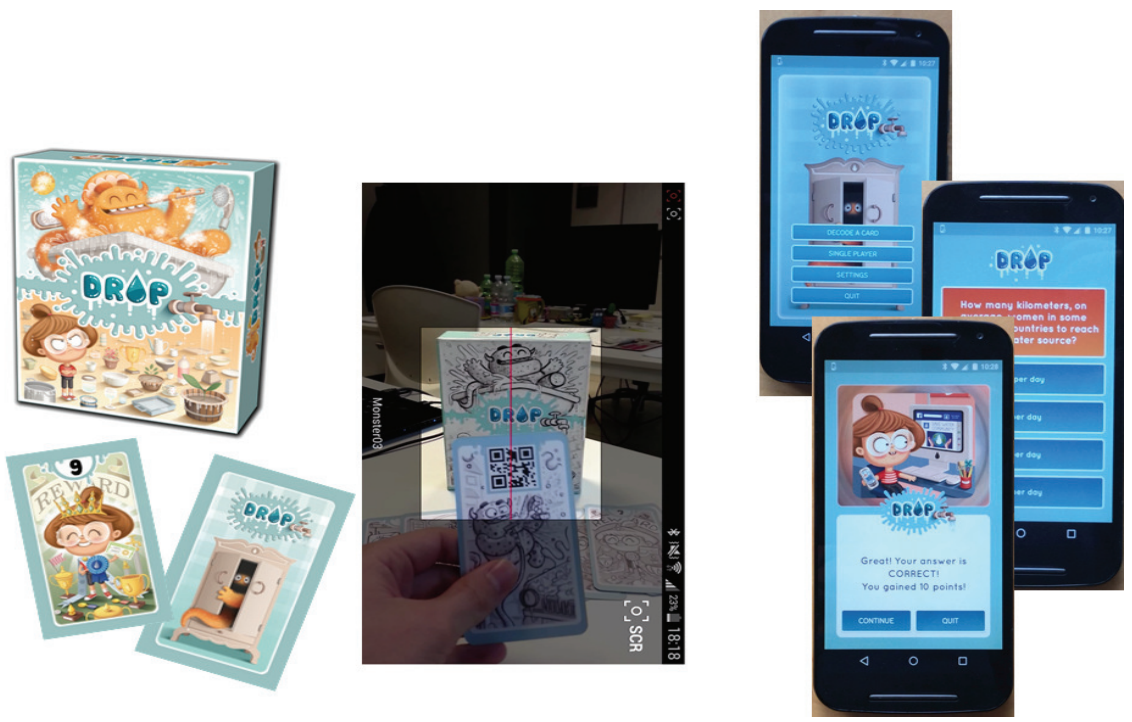

Figure 7. Drop! game integrating physical card game and mobile game.

Apart from the intended motivational and educational effect of the card game, playing the game also incentivizes the use of the web application (the 'SmartH2O portal'), because correctly answered questions in the mobile app yield points on the portal. Playing the game and answering questions increases users' knowledge, which helps to create favourable beliefs about water saving. This supports the contemplation phase where users should be convinced that saving water is necessary and possible. It also stimulates the desire to act appropriately (Lindenberg \& Steg, 2007), as the game associates water saving with achievement and water spilling with losing.

\section{IMPLEMENTATION OF THE SMARTH2O INCENTIVE MODEL FOR WATER SAVING}

The described incentive model has been implemented in the $\mathrm{SmartH} 2 \mathrm{O}$ system as a web application, available in two different versions. The basic portal implements only the "pragmatic" elements, such as the interactive water consumption visualisations and the water saving tips. The gamified portal adds goal setting and the full spectrum of gamified incentives and rewards. The web-based application has been deployed in two different contexts: in the small-scale pilot (Switzerland) it is a new standalone application provided to the customers of the local metering utility, while in the large-scale pilot (Spain) the gamified web application is integrated with the existing customer portal of the local utility company. The same back-end gamification engine serves both cases with two different sets of gamification rules configured for the needs and constraints of each pilot (differing in the type of competition and in the physical rewards as outlined in Chapter 4.3). Table 6 outlines the characteristics of the two pilots.

Table 6. Different implementations and features of the pilots of the SmartH2O system.

\begin{tabular}{|l|l|l|}
\hline & Swiss pilot (small municipality) & Spanish pilot (large city) \\
\hline System version & Basic portal + gamified portal & Gamified portal \\
\hline Potential reach & 400 households with smart meters & 400,000 households with smart meters \\
\hline Main goal & Test system \& incentive model in small-size pilot & Large-scale impact assessment \\
\hline
\end{tabular}




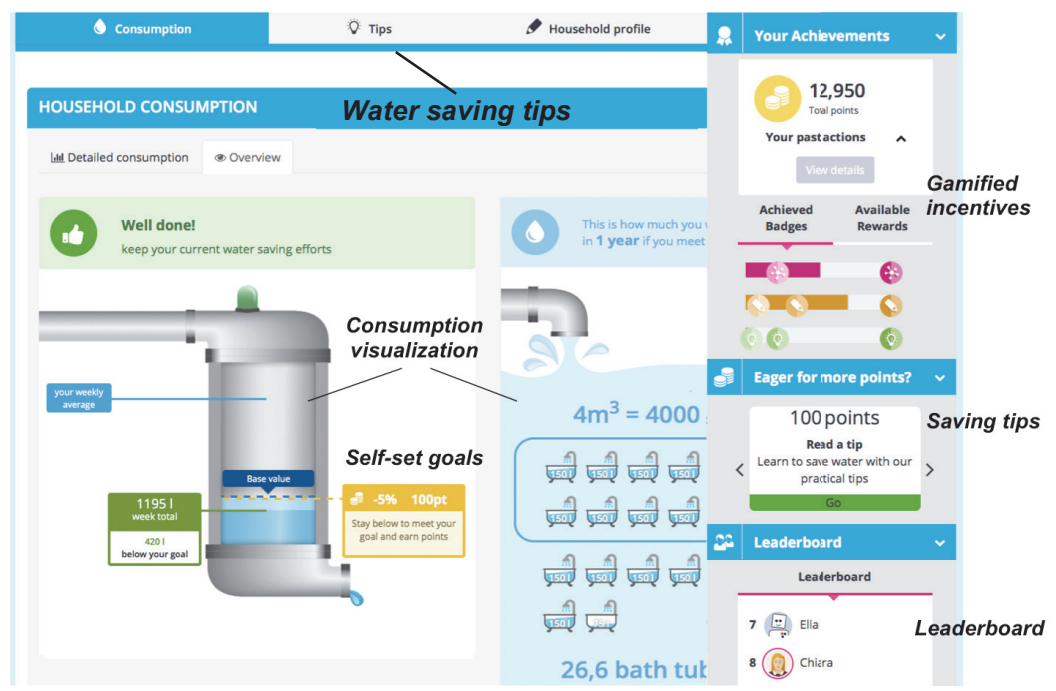

Figure 8. User interface of the SmartH2O portal (gamified version).

Delivery of the incentives is controlled by the Gamification Engine (GE), shown in Figure 9 and Figure 10 , a component that transforms user actions coming from different sources into points, based on a set of inputs and rules (Galli et al., 2015). The different inputs include consumption data from the smart meters, actions and points achieved in the Drop! Mobile game and the user actions performed on the gamified web portal. As shown in the component diagram (Figure 10), the GE rules map individual actions of the consumer (e.g. reading a water saving tip, answering correctly to a question of the Drop! digital game) and achievements (e.g. achieved consumption reduction) to the defined incentive elements through the assignment of points and badges, which are in turn stored into a dedicated database where they can be used for visualization (e.g. of leaderboard and badges) and for the assignment of external rewards (e.g. prizes offered by the utility).

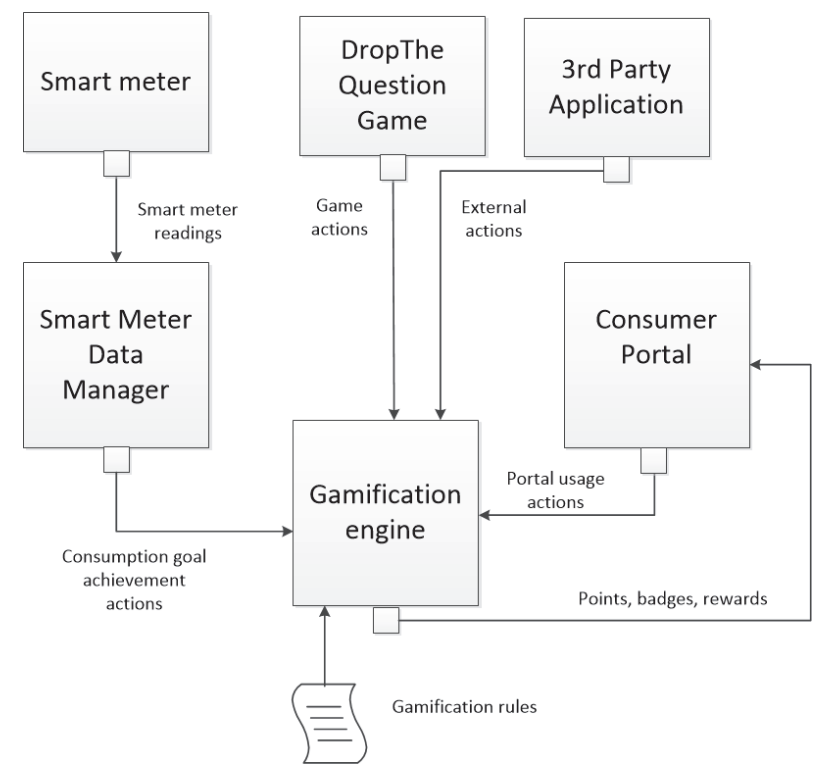

Figure 9. Input and outputs of the rule-based Gamification Engine. 
The core of the GE is in the Gamification Logic Modules, which transform actions into points. All the gamified data are stored in the GE Database, in order to decouple the data from the water utility systems (of a specific pilot) from those managed by the incentive and gamification platform. The Gamification Logic modules of the GE comprise a rule-based engine, which takes inputs from different system modules and produces outputs controlling the gamified incentives. Its main responsibility is to receive the notification of actions performed by the user and decide if, and to what extent, such actions should be rewarded. The Gamification Logic modules can be configured by the administrator to set the type of competition (continuous or periodic), quantifying points associated with actions, and set the rules for actually assigning points and unlocking achievement upon the reception of an action notification (e.g., repeatability and maximum frequency of actions, time constraints, etc.).

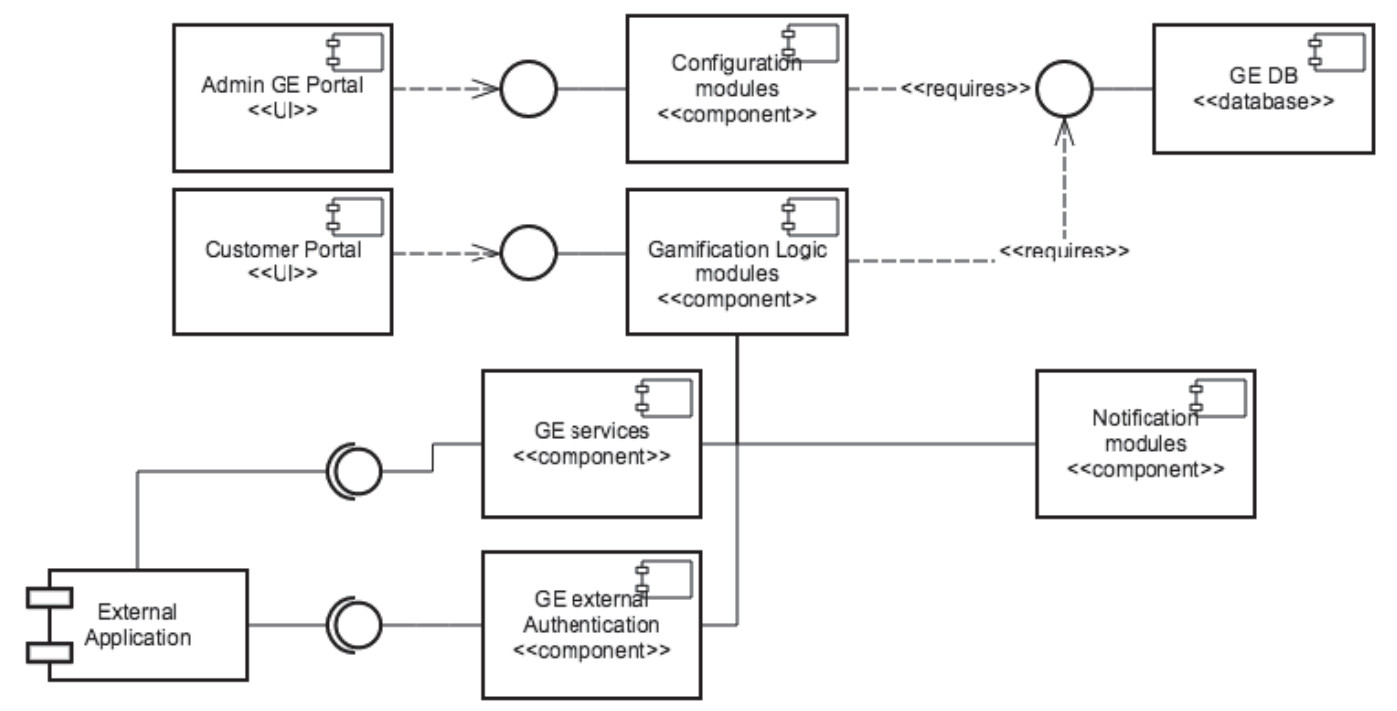

Figure 10. Gamification Engine component diagram.

Four types of actions are distinguished. Consumption actions are derived from the smart meter readings. When the consumption data are received by the smart meter component, they are processed to check whether water saving goals of reducing consumption with a defined percentage over the baseline average consumption of the same period have been achieved (see Table 7).

Portal usage actions are generated as consequences of the user activity in the web application (e.g. logging in, reading a tip, or watching a video). Gameplay actions are produced by the Drop!TheQuestion digital game and correspond to the correct answer to a water education question. External actions produced by external applications can also be incorporated (e.g., when the gamified application is integrated into a pre-existing portal of a water utility that includes other user interactions, such as checking an online bill). Table 7 provides a non-exhaustive illustration of the types of actions defined in the gamification engine and the main configuration parameter (the points) for the two pilots (small scale, large scale). The points are different between the two pilots, due to differences in the scale of the pilot. This scale difference imposes business constraints on the assignment of rewards and also motivates the implementation of a periodic competition scheme in the large-scale pilot (Spain) with weekly rewards assigned to the top performing users only. This differs from the small- 
scale pilot implementation where physical rewards can be continuously collected by achieving a set number of points (see reward mechanisms description in Chapter 4.3).

Table 7. Action sources in the Gamification Engine and their parametric value in the two pilots.

\begin{tabular}{|l|l|l|r|r|}
\hline Actions & Source & Thematic area & Score in CH & Score in ES \\
\hline Water saving actions & & & & \\
\hline Weekly savings: & & & 50 & 1500 \\
\hline Weekly Savings 5\% (automatic) & Consumption & Water Saving & 150 & 4500 \\
Weekly Savings 10\% (automatic) & & & 450 & 13500 \\
Weekly savings 15\% (automatic) & & & 100 & 3000 \\
\hline Weekly Goal 5\% (set by the user) & Consumption & Water Saving & 300 & 9000 \\
Weekly Goal 10\% (set by the user) & & & 900 & 27000 \\
Weekly Goal 15\% (set by the user) & & & 100 & 100 \\
\hline Water saving insights & & & 100 & 100 \\
\hline \hline Read water saving tip & Portal usage & Water Saving insight & & \\
\hline Correct answer on Drop!TheQuestion & Portal usage & Water saving insight & & \\
mobile app & & & & \\
\hline Engagement & & & 300 \\
\hline Login & Portal usage & Engagement & & 300 \\
\hline Download of Drop!TheQuestion mobile & Game & Engagement & & 2500 \\
\hline app & & & & \\
\hline Switch from paper-bill to electronic bill & External & Engagement & & \\
\hline \hline Participation actions & & & & \\
\hline Enter Top 3 of overall Leaderboard & Portal usage & Engagement & & \\
\hline
\end{tabular}

\section{PRELIMINARY RESULTS FROM A SMALL-SCALE PILOT}

The SmartH2O system has been first deployed in a small-scale pilot in Switzerland. In this paper we analyse the period spanning from July 2015 to February 2016. A first basic version of the web portal with only consumption visualisation and water saving tips was published in July 2015 , followed by the fully gamified version of the portal, deployed at the beginning of December 2015 (Figure 11).

The validation set-up of the small-scale pilot in Switzerland was based on two interim validations and a final validation. For evaluating the impact of the system on water consumption, the consumption during the respective observation period was compared against the historical baseline consumption. A comparison of the intervention group consumption (system users) with the consumption of a sample of inhabitants who didn't use the system was also performed ${ }^{7}$. User feedback was collected through a

7 The establishment of a full-fledged control group wasn't feasible due to the small overall sample (400 households with smart meters were available in total) and the difficulty to isolate the recruitment campaign for system users from the control group recruitment (small geographically contained municipality). Moreover, initially the utility couldn't guarantee providing the consumption data of the non-users. Eventually, we were able to obtain (anonymized) consumption data for 170 smart metered households that didn't use the system, and used this to verify the attribution of system effect on water consumption (see Section 6.3). The user questionnaires couldn't be administered to these non-users. 
questionnaire administered to the portal users, containing items regarding technology acceptance on both the level of the application as a whole, and on the level of the individual features of the portal. On application level, technology acceptance was measured using the UTAUT framework (Venkatesh et al., 2003), with items adapted to match the context of use in the water domain. Additionally, hedonic and pragmatic quality were measured using Hassenzahl's AttrakDiff2 questionnaire (Hassenzahl, 2004). The feature-level questionnaire contained questions about the perceived ease-of-use, usefulness and motivation effect of most important features (where appropriate). In addition to the questionnaires, the usage of the portal was analysed using system log files.

The users were recruited through a recruitment campaign conducted with the collaboration of the municipal water utility of Terre di Pedemonte. In the early stages of the project, a public workshop was held, where all citizens were invited. This workshop was also useful to elicit important requirements for the platform functionalities. Before the platform launch, a newsletter was sent by the water utility to all households that were equipped with a smart meter (400 houses), informing them of the forthcoming release of the SmartH2O platform. Finally, following the release a personalised letter containing the credentials to activate the link between the smart water meter and the platform was sent to all those households.

The first interim validation took place after four-months of the trial, evaluating the basic portal involving 40 users (households). The overall response rate to joining the trial was thus $10 \%$, while the online questionnaire yielded 15 responses (response rate of $37,5 \%$ ). This questionnaire was submitted to the users before upgrading the basic system to the second release (Figure 11) that replaced the first overview visualisation with the water pipe metaphor visualisation (see Chapter 4.1). In this section, we address the user feedback from the first interim validation questionnaire, as well as the preliminary impact on water consumption. Finally, we provide a preliminary outlook on the user response to the gamified portal by analysing the system usage logs from December 2015 to February 2016. The timeline of the web portal deployment is summarized in Figure 11.

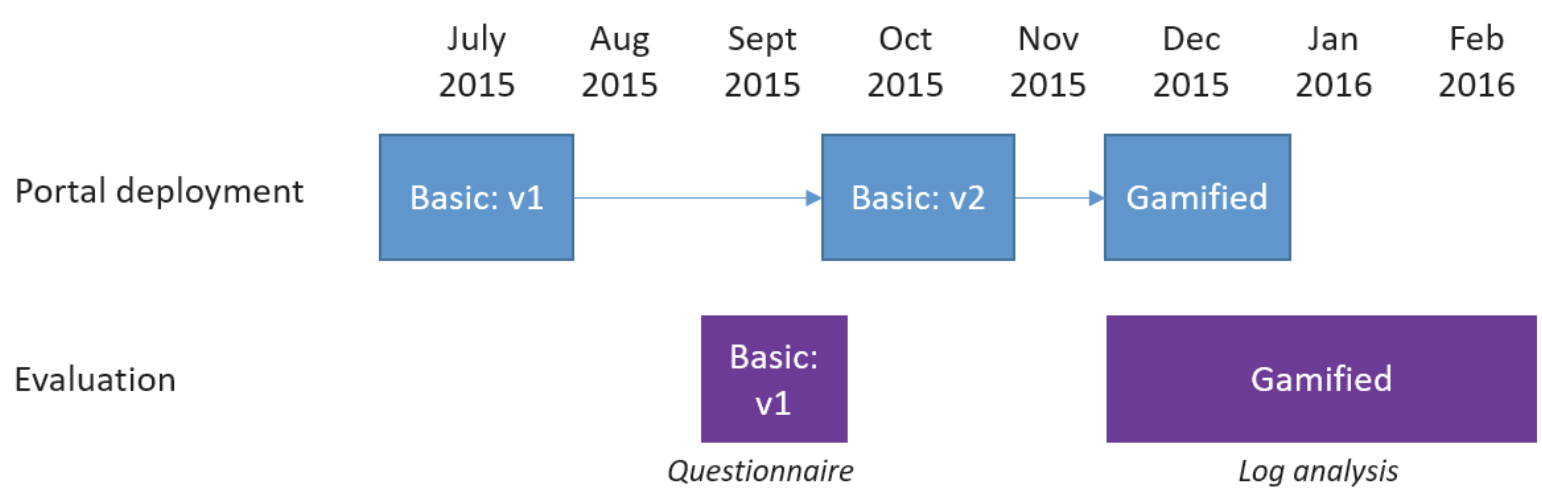

Figure 11. Deployment timeline for the small-scale pilot. 


\subsection{User acceptance of the system}

To measure user acceptance on the level of the application as a whole, the users' attitude towards technology, effort expectancy (i.e. perceived ease-of-use), and performance expectancy (i.e. perceived usefulness) were measured by means of the respective sub scales from the UTAUT framework (Venkatesh et al., 2003). Questionnaire items were adapted to match the context of use in the water domain. All questions were asked on a five-point Likert scale, ranging from strongly disagree to strongly agree. The results are summarized in Table 8 in a commonly used format. The effort expectancy results demonstrate that for the majority of the respondents the portal was easy to learn using ( 11 out of 15 agreed or strongly agreed; $m=3.9$; s.d.=.7) and easy to use (12 out of 15 agreed or strongly agreed; $m=4.0 ; s . d .=.6)$. The majority also found that the interaction with the system was clear and understandable ( 9 out of 15 agreed or strongly agreed; $m=3.8 ; s . d .=.7$ ) and that it was easy to get skilful at using the system ( 8 out of 14 agreed or strongly agreed; $m=3.8$; s.d.=.8). That confirms the usability of the system design.

Table 8. User acceptance results (UTAUT).

\begin{tabular}{|c|c|c|c|c|}
\hline UTAUT construct & Item & Mean & S.d. & Median \\
\hline \multirow[t]{4}{*}{$\begin{array}{l}\text { Performance } \\
\text { expectancy }\end{array}$} & $\begin{array}{l}\text { My interaction with the SmartH } 2 \mathrm{O} \text { portal is clear and } \\
\text { understandable. }\end{array}$ & 3.8 & .7 & 4.0 \\
\hline & Learning how to use the $\mathrm{SmartH} 2 \mathrm{O}$ portal is easy for me. & 3.9 & .7 & 4.0 \\
\hline & I find the SmartH2O portal easy to use. & 4.0 & 6 & 4.0 \\
\hline & It is easy for me to become skilful at using the SmartH2O portal. & 3.8 & .8 & 4.0 \\
\hline \multirow{4}{*}{$\begin{array}{l}\text { Attitude towards } \\
\text { the technology }\end{array}$} & Using the SmartH2O portal is a good idea. & 3.9 & .7 & 4.0 \\
\hline & The system makes water conservation more interesting. & 3.8 & .5 & 4.0 \\
\hline & I like using the system. & 3.5 & .7 & 3.0 \\
\hline & Using the system is fun. & 3.5 & .6 & 3.0 \\
\hline \multirow[t]{2}{*}{ Effort expectancy } & I find the SmartH2O portal useful in my daily life. & 3.2 & .7 & 3.0 \\
\hline & $\begin{array}{l}\text { Using the SmartH } 2 O \text { portal increases my chances of achieving } \\
\text { things that are important to me. }\end{array}$ & 3.5 & 6 & 3.0 \\
\hline
\end{tabular}

Regarding the respondents' attitude towards technology, the results revealed that the system makes water conservation more interesting (11 out of 15 agreed or strongly agreed; $m=3.8$; s.d.=.5) and that using it is a good idea (9 out of 15 agreed or strongly agreed; $m=3.9$; s.d.=.7). Curiously, most respondents were undecided about whether they like using the system (10 out of $15 ; m=3.5 ; s . d .=.7$ ), while at the same time almost half of them found that it is fun using the system ( 7 out of $15 ; m=3.5$; s.d.=.6). Keeping in mind that the respondents were reporting on the basic system, the latter indicates that already water consumption feedback and tips appeal to users, even without gamified elements.

On the other hand, the absence of the overall "liking" of using the system, in spite of the overall very good ratings on the other usability aspects suggests that the additional motivational affordances, foreseen in the gamified design were indeed needed, in order to increase fun-of-use and engagement with water saving - even for target groups who initially declared valuing primarily pragmatic usefulness rather than hedonic aspects (uncovered in the requirements analysis outlined in Chapter 3 ). 
This is also confirmed by the results of the hedonic quality questionnaire (AttrakDiff2, Hassenzahl, $2004)^{8}$, showing that the perceived pragmatic quality (PQ) of the basic system was higher than its hedonic stimulation quality (HQ-S), even though the latter is higher than for an average system $(P Q=5,3$ vs. $H Q-S=4,9)$. Since the basic version without gamified elements was explicitly designed to meet the needs of more pragmatically oriented users, the high $P Q$ score confirms that this goal has been reached, while also hinting at additional potential of the gamified version even for self-declared "non-playful" users (see user activity analysis for the gamified version in Chapter 6.3).

Another potentially critical aspect concerns the performance expectancy results. Respondents were undecided regarding the usefulness of the system in their daily life (11 out of $15 ; \mathrm{m}=3.2$; s.d.=.7) and regarding the extent to which the systems increases their performance in achieving things that are important to them (only 6 agreed with 9 undecided; $m=3.5$; s.d.=.6).

These results are likely attributable to the relatively limited period of exposure to the system (up to 4 months at the moment of questionnaire submission) which seems to have initiated the behavioural change process, but which needs more time to take place and more strongly influence underlying habits and attitudes. This explanation is in accordance with Dahlstrand \& Biel (1997) who have emphasized the multi-phased and complicated nature of changing habitual environment-related behaviour that starts with exposure (e.g. attracting attention), and ends with the formation of new, sustainable habits.

Given the observed frequencies of use of the portal in the trial (Chapter 6.4) and the observed reductions in water consumption (Chapter 6.3), though first promising effects of user engagement can be observed, it is unlikely that users have already advanced through the whole behavioural change process and formed new habits. This is also in line with overwhelmingly positive user responses to the usefulness of the individual elements of the system such as the consumption visualisation and water saving tips, discussed in the next section.

\subsection{User feedback on consumption visualisations and tips}

Most respondents found the interactive water consumption chart easy to use (Figure 12 left) and nearly all respondents agreed that from the chart and the overview visualisation they could understand how much water their household consumed over time (Figure 13). They found the water saving tips rather useful, but were neutral regarding the extent to which they were able to put them into practice (9/14 users). This was to be expected since the tips were of varying complexity and household characteristics. The impact of different water saving tips needs to be investigated in more detail in upcoming evaluations. The perceived usefulness of the three main elements (water consumption chart, first version of the consumption overview, and water saving tips) was rather positive for most users (Figure 12, right). For all three features we also observed a positive perceived influence on increasing water saving awareness, as most users stated that they made them think about water conservation more often (Figure 14).

\footnotetext{
8 The pragmatic quality and hedonic quality (stimulation) were measured using seven seven-point bipolar scales ranging from e.g. harmful (1) to beneficial (7).
} 


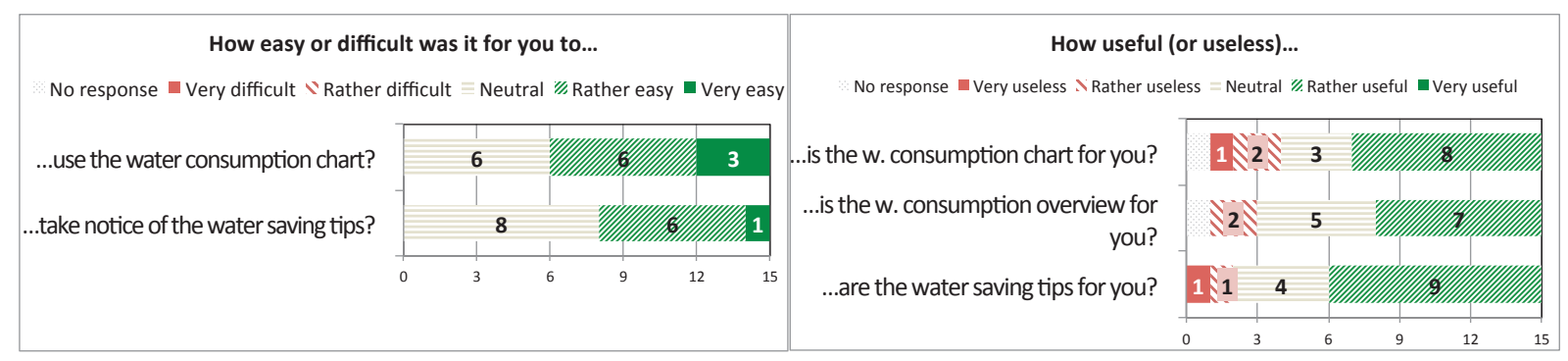

\section{Figure 12. Ease of use $(I)$ and usefulness ( $r$ ) of consumption visualisations and saving tips.}

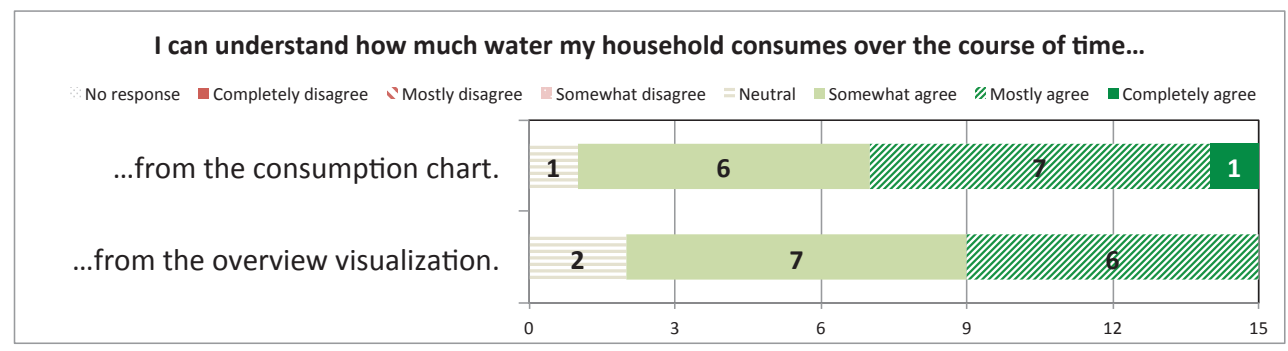

Figure 13. Understanding of consumption visualisations.

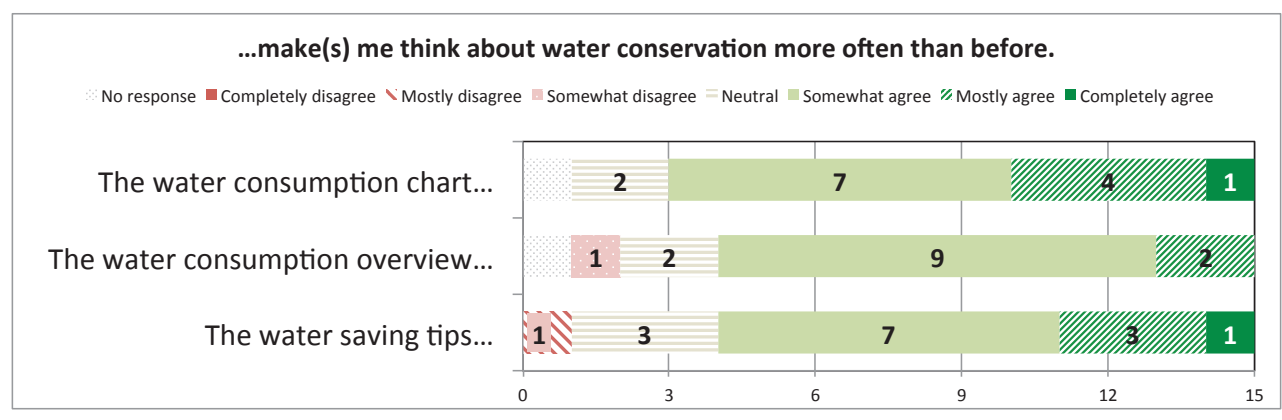

Figure 14. Perceived awareness increase of consumption visualisations and saving tips.

\subsection{Preliminary assessment of impact on water consumption}

As the basis for assessing the impact of the SmartH2O system on water consumption, consumption baselines (i.e. daily, weekly, and monthly average consumption volumes) were collected, starting from the moment a smart meter was installed. On average this period comprised 255.0 days (s.d. 55.9). After computing the average daily consumption, the collected baseline data were used to classify users into low, low/medium, medium/high or high consumption classes, following the approach explained in (Bertocchi et al., 2016). Eight users were identified as outliers and removed from the sample, due to either their smart meter being installed too late to have sufficient and reliable baseline data, or their house not being used regularly (e.g. summer houses). Water consumption was then monitored for the remaining 35 users during a three-month observation period in winter 2015 (after the launch of the second version of the basic portal; Figure 11). The average daily consumption from this period was compared against the average baseline consumption. In Table 9 the observed average consumption reduction is displayed for each of the consumption classes (classes differ in size due to the small scale of the pilot). 
Table 9. Water saving per class of consumers in the Swiss small-scale pilot.

\begin{tabular}{|l|l|r|r|r|r|}
\hline $\begin{array}{c}\text { Consumption } \\
\text { class }\end{array}$ & $\mathbf{N}$ & $\begin{array}{c}\text { Average daily water } \\
\text { consumption }\left(\mathbf{m}^{3}\right)\end{array}$ & $\begin{array}{c}\text { Average } \\
\text { reduction (\%) }\end{array}$ & \multicolumn{1}{|c|}{ S.d. } & \multicolumn{2}{c|}{$\begin{array}{c}\text { No. of users with } \\
\mathbf{3 0 \%} \text { reduction }\end{array}$} \\
\hline Low & 6 & 0.18 & 25.7 & 20.5 & 2 \\
\hline Low/medium & 19 & 0.47 & 23.4 & 26.0 & 5 \\
\hline Medium/high & 8 & 0.89 & 38.5 & 16.9 & 1 \\
\hline High & 2 & 1.75 & 42.0 & & 17 \\
\hline Total & $\mathbf{3 5}$ & $\mathbf{0 . 5 4}$ & $\mathbf{2 7 . 5}$ & $\mathbf{2 4 . 4}$ & \\
\hline
\end{tabular}

Results show that the average absolute consumption is $0.54 \mathrm{~m}^{3} /$ day and that the highest reductions are achieved by users with medium-high or high consumption. While the average reductions seem encouraging, due to a limited period of measurement (three months, no summer period), possible seasonal effects of $25-30 \%$ (e.g. Firat et al., 2009) would need to be discounted to assess the actual reduction induced by the system. On the other hand, we have also analysed the consumption of the users who did not use the SmartH2O system ${ }^{9}$. Their average consumption over the same period was $0.49 \mathrm{~m}^{3} /$ day (slightly lower than the one of the intervention group), and the observed average reduction was $8 \%$, i.e. much lower than that of the intervention group $(27.5 \%)$. Thus, even without being able to more precisely isolate the seasonality effect, the observed difference in the consumption reduction between the SmartH2O users and consumers who didn't use the system suggests that the system usage had the observed (relative) impact on water consumption. However, given the limited duration of the observed trial period, a more reliable analysis can only be done on the basis of consumption data for an entire year of the trial.

\subsection{Preliminary analysis of user activity for the gamified portal}

The main objectives of this pilot phase have been to recruit a core user group in a rather conservative population, and familiarize this group with the portal in anticipation of the future extension of the pilot to a larger community. The initial recruitment campaign (public workshop, newsletter and personalised letters) resulted in 27 basic portal users. In the final recruitment campaign coinciding with the release of the gamified portal personalised letters were again sent to all the households with smart meters, inviting them to sign-up (or upgrade) to the gamified version of the system. The campaign was targeted at recruiting both new and current users of the basic portal. The campaign has yielded 16 gamified portal users ( 6 of these were already users of the basic portal), whose activity on the portal has been examined to gain a first insight into the user interactions with the elements of the implemented incentive model. For that purpose, usage logs over a 10 week period, from the launch of the gamified portal version in December 2015 to February 2016 have been analysed.

9 To this end, we were able to obtain (anonymized) consumption data for a sample of 170 smart metered households that neither used, nor had registered for using the system. The sample included households whose smart metered data was collected regularly and reliably by the utility, with same data cleaning as for the system users (removing outliers, rarely used summer houses and households with irregular data transmission). 
After the launch of the gamified portal in December, little activity occurred on the basic portal (20 logins; $m=.74 /$ user; median=0; s.d.=1.9), whereas the activity on the gamified version of the portal was substantially higher (292 logins; $m=18.25 /$ user; median=2.5; s.d.=43.6). A Mann Whitney $U$ test revealed that the difference between basic portal and gamified portal users was statistically significant with respect to the number of logins $(U=39.5 ; Z=-4.73 ; p<.001)$. As reflected in the large standard deviation and in the difference between the mean and the median values, the login frequency is highly skewed. This is due to a small number of highly active users, who strongly influenced the usage dynamics (see discussion further below). Further analysis of the data also showed that activity peaked after a reminder e-mail campaign to current users. Even though the small number of users requires caution in drawing conclusions, this result suggests that the gamification features can prompt more interest in the portal, while promotional campaigns can be an effective way to further stimulate engagement with behavioural change systems for water consumption, such as SmartH2O.

Both the basic portal and the gamified portal prompt users to inspect their water consumption through an adjustable bar chart, and through a display that employs a pipe metaphor (see Section 4.1). The log data show that the consumption chart has been viewed and interacted with the most. In the analysis, only users who have logged in more than once have been considered. Basic portal users viewed the consumption chart page on average 1.5 times over the course of the observed validation period (median=1.5, s.d.=.7), compared to 16.7 times (median=2, s.d.=26.9) for the gamified portal users. Basic portal users inspected the overview page on average 2.0 (s.d.=.7) times, whereas gamified portal users visited this page on average 13 times (median=3; s.d.=18.3). A Wilcoxon signed rank test demonstrated that the difference between basic portal and advanced portal users was not significant $(Z=-1.69 ; p>.05)$. The large standard deviation and the difference between the mean and the average point to strong variations between the users, pointing to a commonly found pattern in such behavioural change systems where lead users can be observed to be substantially more active than the majority of the other users. Finally, it should be noted that the gamified consumption overview page required an additional user action, because it is placed in a different tab than the bar chart, which is displayed by default.

Subsequently, we analysed the 16 users who used the gamified portal (10 were new users who registered directly for the gamified portal, while 6 users upgraded from the basic portal). Figure 15 displays the number of users who have used the gamified portal features more than once. The data reveal that key elements of the gamified portal were accessed more than once by a significant share of the users: this includes the leaderboard (10/16), the achievements and action panels (10/16), and the profile page (11/16). Only four users have visited the rewards page more than once. This could be due to the limited time the portal has been online, and thus to the limited opportunity to collect points for claiming rewards. Almost half $(7 / 16)$ of the users have visited the tips page once or more over the observation period $(m=16.9$; median=2; $s . d .=32.2$ ). Two users frequently visited the tips page (94 and 45 times). Without them, the remaining users accessed the tips page on average only 0.9 times (s.d. 2.7, median=2). 


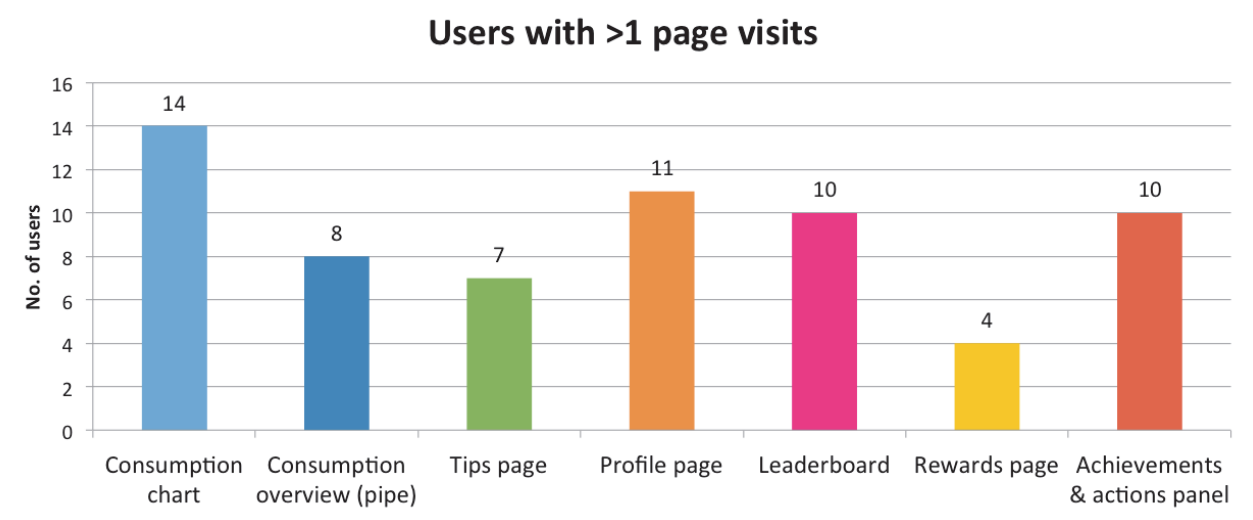

Figure 15. Break-down of platform usage, divided by feature.

Finally, all but three advanced portal users collected badges (13/16). The users who collected the badges, collected on average 3.6 badges (median=4.0; s.d.=1.7). These indicators suggest that the gamified system appeals to this initial user base, and that the incentive model is capable of motivating users to access and use the system, and thus of engaging them with water consumption information. Additionally, the data demonstrate different patterns of usage, with a subset of users being substantially more active than others.

The logs of system activity allowed for the identification of several lead users that displayed a high level of activity, but with rather different usage patterns. Lead user analysis is commonly used to identify early adopters and observe patterns of behaviour that give examples of possible behaviour types of active users in the future enlarged user population. Lead users also have an important role for stimulating the user community dynamics: they are not simply outliers, but most active users who are crucial for providing a core activity on the portal that influences the impression of the system by other users, and thus also their (re)actions. This often results in stimuli for other users to become more active, prevents the impression of "dead" usage periods on the portal, and supports continuous dynamics of the competitive gamification elements (e.g. leaderboard, competitive rewards). In our case, two main lead users were identified: one has logged in 176 times and the other 21 times over a ten-week interval. To illustrate their behavioural patterns, in Figure 16 we have plotted their portal usage and interaction with the gamified elements against time.

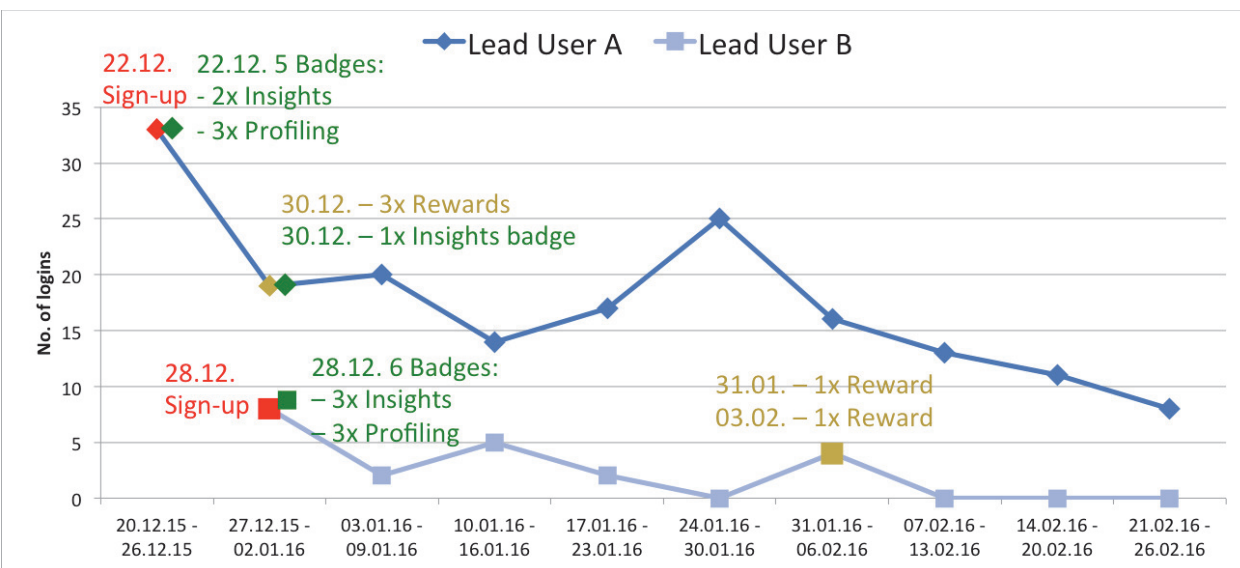

Figure 16. Engagement with gamified incentive model elements of two lead users. 
Figure 16 shows that lead user \#1 earned all his/her badges within a very short time, and after a short period of intense usage claimed the available rewards all at once, shortly after earning the necessary points. Yet s/he continued to login frequently, viewing his/her consumption chart and checking the leaderboard during most visits. This suggests that the user was intrinsically motivated by the combination of consumption feedback and gamification features. The second lead user earned his/her badges on the same day as his/her sign-up, but continued to frequent the portal at a moderate pace until s/he reached enough points to redeem the main reward. Shortly after, s/he stopped using the portal, which suggests that this usage was mainly driven by the high external reward. Interestingly, this user achieved only $18.2 \%$ consumption reduction, compared to $52.5 \%$ of the other lead user, not driven primarily by external rewards. While we cannot solely attribute such consumption reductions to portal usage (there is e.g. an obvious vacation gap in both charts, and other external factors also can have played a role), the observed patterns indicate that portal usage has likely influenced these lead users over the entire analysed period of the pilot.

Overall, the observed dynamics of system use suggests that the implemented gamified incentive model successfully addressed different types of users. This includes a few highly active users, but with different motivational patterns (the two very different lead users), as well as a positive response, but less frequent activity of the remaining users (e.g. 13 out of 16 users collecting on average 3.6 badges, median=4; s.d.=1.7). Similarly, if the lead users are excluded from the analysis, the average number of views of the tips page declines dramatically ( 0.9 vs. 16.9), while its median value ( 2 views) remains the same with and without the two lead users (median $=2$ ). On the other hand, the observed average frequency of logins after excluding the lead users is still relatively high (6.8 monthly logins on average, s.d.=11.6, median=2), in particular when compared to available results for similar consumption feedback portals. For example, in Gölz (2017) an average of 1.0-3.0 monthly logins for the majority of users has been reported in a trial with an energy consumption feedback portal (with the exception of a group of highly active users with 10.8-14.8 monthly logins). Such type of results for comparable systems in the water domain haven't yet been reported, although field studies with in-situ feedback (e.g. on-shower devices) have reported high levels of engagement (e.g. Tiefenbeck et al., 2016). Overall, given the small user sample, the limited duration of the observed trial period in our case and the frequently observed decline of the intensity of usage with longer trial duration (Gölz, 2017, Gölz \& Hahnel, 2016), the discussed results are promising, but need to be taken with caution. More reliable conclusions are expected after the final evaluation of the entire year of the trial.

\section{CONCLUSIONS}

In this paper we have presented the theoretical underpinnings and the design of a behavioural change system for stimulating water saving by combines smart-meter based consumption visualisation, water saving tips and gamified incentives. We have shown how the design of such a system can be informed by different motivational theories and systematically related to a holistic behavioural change process model to obtain an integrated incentive model combining different types of incentives (virtual, 
physical, social). The described implementation demonstrates a practical realization of the developed model and shows how it can be adapted to different types of settings (small scale, large scale).

The discussed results from a preliminary evaluation in a real-world, small-scale setting suggest that the designed incentive model and its systematic alignment with the adopted behavioural change process are suitable for stimulating water saving and initiating the behavioural change process. The observed positive effects on water consumption are encouraging, but must be taken with due caution due to the small user sample and limited duration of the trial. The positive user feedback to the individual elements of the incentive model and its implementation in the SmartH2O system suggests that they make water conservation more interesting. The consumption visualisation and water saving tips have reportedly make users think more often about water consumption and made it easy to understand it. The higher user activity on the gamified portal compared to the basic version without gamification suggests that the incorporated gamified design and incentives can stimulate user engagement, while the results of the lead user analysis point to their capability to accommodate different patterns of user behaviour. Such observations suggest that the designed gamified incentive model is versatile enough to stimulate different types of users.

The overall results suggest that even with a small user community and not a very long period for the incentive model to yield effects, the system was able to trigger different participation dynamics. Differences in responses to the incentive model highlight the importance of a holistic approach that comprises different motivational affordances to support the behavioural change process for all users. Similarly, the results regarding the hedonic and pragmatic affordances of the implemented system suggest that such systems supporting behavioural change for water saving should indeed combine both utilitarian and hedonic types of usage. Though preliminary in nature, the presented approach and results can thus already inform the further development of such systems and approaches to encourage end-user water saving.

The presented results and analysis are subject to several limitations that need to be addressed in further studies. These include the small user sample and the limited period of the system trial, as well as the need to more closely analyse how specific types or patterns of user interaction with the system may be related to observed (patterns of) consumption reduction. Similarly, the change in user attitudes and behaviour towards water saving as proxies for a user's progress through stages of the behavioural change process should be measured and analysed (though not easy to perform). Some of these are subject of our on-going large-scale trial.

\section{ACKNOWLEDGMENTS}

This work was partially supported by the European Commission FP7 programme [grant agreement number 619172]. The authors wish to thank Corrado Valeri, who has provided a valuable assistance in preparing the water consumption data for the analyses. We also thank the anonymous reviewers for their helpful comments. 


\section{REFERENCES}

1. Abrahamse, W., Steg, L., Vlek, C., \& Rothengatter, T. (2005). A review of intervention studies aimed at household energy conservation. Journal of Environmental Psychology, 25(3), 273-291.

2. Abrahamse, W., Steg, L., Vlek, C., Rothengatter, T., 2007. The effect of tailored information, goal setting, and tailored feedback on household energy use, energy-related behaviors, and behavioral antecedents. J. of Env. Psychology, 27 (4), 265-276.

3. Ai He, H., Greenberg, S., \& Huang, E. (2010). One size does not fit all: applying the transtheoretical model to energy feedback technology design. Proc. SIGCHI Conference on Human Factors in Computing Systems CHI'10, 927-936.

4. Ajzen, I., 1991. The theory of planned behavior. Organiz. behav and human decision proc, 50(2), 179-211.

5. Arroyo, E., Bonanni, L., Selker, T., 2005. Waterbot: exploring feedback and persuasive techniques at the sink. Proc. of the SIGCHI Conference on Human Factors in Computing Systems, Portland, Oregon, USA.

6. Atkinson, J. W., Litwin, G. H., 1960. Achievement motive and test anxiety conceived as motive to approach success and motive to avoid failure. J. of Abnormal and Social Psychology, 60 (1), 52-63.

7. Bamberg, S., 2013. Changing environmentally harmful behaviors: A stage model of self-regulated behavioral change. J. of Environmental Psychology, 34, 151-159.

8. Bandura, A., 1977. Self-efficacy: Toward a unifying theory of behavioural change. Psych Review, 84 (2):191215.

9. Buchanan, K., Russo, R., \& Anderson, B. (2015). The question of energy reduction: The problem(s) with feedback. Energy Policy, 77, p. 89-96.

10. Burgess, J., Harrison, C. M., \& Filius, P. (1998). Environmental communication and the cultural politics of environmental citizenship. Environment and Planning A, 30(8), p. 1445-1460.

11. Chambers, N., Coakley, D., McCaffrey, M., Curry, E., Keane, M., Costa, A. \& Clifford, E. (2015). Assessment and Planning for the Application of Fault Detection and Diagnosis (FDD) to Building Water Networks, A WATERNOMICS Approach, Proceedings of the 36th IAHR World Congress (IAHR 2015). The Hague, the Netherlands, 2015.

12. Clifford, E, Coakley, D, Curry, E, Degeler, V, Costa, A, Messervey, Mink, J., 2014. Interactive water services: the waternomics approach. Procedia Engineering, 89, 1058-1065.

13. Cominola, A., et al., 2015. Benefits and challenges of using smart meters for advancing residential water demand modelling and management: A review. Environmental Modelling \& Software, 72, 198-214.

14. Corral-Verdugo, V., Bechtel, R.B, Fraijo-Sing, B., 2003. Environmental beliefs and water conservation: An empirical study. J. of Environmental Psychology, 23 (3), 247-257.

15. Dahlstrand, U., Biel, Anders, B., 1997. Pro-Environmental Habits: Propensity Levels in Behavioral Change. J. of Applied Social Psychology, 27 (7), 588-601.

16. Deci, E.L., Ryan, R.M., 1985. Intrinsic motivation and self-determination in human behaviour. New York: Plenum.

17. Deterding, S., Dixon, D., Khaled, R., Nacke, L., 2011. From game design elements to gamefulness: defining "gamification". Proc.15th International Academic MindTrek Conf. ACM, Tampere, Finland, pp. 9-15.

18. Elliot, A. J., \& Covington, M. V. (2001). Approach and Avoidance Motivation. Educational Psychology Review, 13(2), p. 73-92.

19. Ferraro, Paul J., and Michael K. Price (2013). Using nonpecuniary strategies to influence behavior: evidence from a large-scale field experiment. Review of Economics and Statistics 95.1 (2013): 64-73.

20. Fielding, K.S., Russell, S., Spinks, A, Mankad, A., 2012. Determinants of household water conservation: The role of demographic, infrastructure, behavior, and psychosocial variables. Water Resources Research, 48 (10). 
21. Fielding, K.S., Spinks, A., Russell, S., McCrea, R., Stewart, R., Gardner, J., 2013. An experimental test of voluntary strategies to promote urban water demand management. $J$ of Env Management, 114, 343-351.

22. Firat, M., Yurdusev, M. A., Turan, M. E., 2009. Evaluation of artificial neural network techniques for municipal water consumption modeling. Water resources management, 23 (4), 617-632.

23. Fraternali, P., Baroffio, G., Pasini, C., Galli, L., Micheel, I., Novak, J., Rizzoli, A.E., (2015). Integrating Real and Digital Games with Data Analytics for Water Consumption Behavioral Change: A Demo. Proc. IEEE UCC 2015

24. Fréjus, M., \& Martini, D. (2016). Why Energy Consumption Feedback Is not (Only) a Display Issue. In A. Marcus (Ed.), Lecture Notes in Computer Science. Design, User Experience, and Usability: Novel User Experiences (Vol. 9747), pp. 461-471.

25. Froehlich, J., Findlater, L., Ostergren, M., Ramanathan, S., Peterson, J., Wragg, Landay, J. A., 2012. The design and evaluation of prototype eco-feedback displays for fixture-level water usage data. In. Proc ACM CHI 2012

26. Galli, L., Fraternali, P. Pasini, C., Baroffio, G., Dos Santos, A.D., Acerbis, R. Riva, V., 2015. A gamification Framework for Customer Engagement and Sustainable Water Usage Promotion. Proc. IAHR 2015, The Hague

27. Gölz, S. (2017). Does feedback usage lead to electricity savings? Analysis of goals for usage, feedback seeking, and consumption behavior, Energy Efficiency (2017): 1-21.

28. Gölz, S., Hahnel, U.J.J. (2016). What motivates people to use energy feedback systems? A multiple goal approach to predict long-term usage behaviour in daily life." Energy Research \& Social Science 21 (2016): 155-166.

29. Hassenzahl, M. (2004). The Interplay of Beauty, Goodness, and Usability in Interactive Products. HumanComputer Interaction, 19(4), 319-349.

30. Hassenzahl, M. (2008): User experience (UX): towards an experiential perspective on product quality. In: 20th International Conference of the Association Francophone d'Interaction Homme-Machine, pp. 11-15. Metz, France

31. Jorgensen, B., et al., 2009. Household water use behavior: An integrated model. J.of Env. Mngmt, 91(1),227236.

32. Kappel, K., Grechenig, T., 2009. Show-me: water consumption at a glance to promote water conservation in the shower. In Proc. of the 4th international conf on persuasive technology, p. 26.

33. Katz, D., Grinstein, A., Kronrod, A., \& Nisan, U. (2016). Evaluating the effectiveness of a water conservation campaign: Combining experimental and field methods. Journal of Environmental Management, 180, 335343.

34. Kenway, S. J., Binks, A., Lane, J., Lant, P. A., Lam, K. L., \& Simms, A. (2015). A systemic framework and analysis of urban water energy. Environmental Modelling \& Software, 73, 272-285.

35. Laschke, M., et al., 2011. With a little help from a friend: a shower calendar to save water. In ACM CHI'11 Ext. A.

36. Lindenberg, S., Steg, L., 2007. Normative, Gain and Hedonic Goal Frames Guiding Environmental Behavior. J. of Social Issues, 63 (1), 117-137.

37. Ling, K., Beenen, G., Ludford, P., Wang, X., Chang, K., Li, X., ... \& Resnick, P. (2005). Using social psychology to motivate contributions to online communities. Journal of Computer-Mediated Communication, 10(4), p.

38. Locke, E. A., Shaw, K. N., Saari, L. M., \& Latham, G. P. (1981). Goal setting and task performance: 19691980. Psychological bulletin, 90(1), p. 125-152. 
39. Micheel, I., Novak, J., Fraternali, P., Baroffio, G., Castelletti, A., Rizzoli, A.E., 2015. Visualizing and Gamifying Water and Energy Consumption for Behavior Change. IFIP INTERACT 2015 Adjunct Proceedings.

40. Mitchell, D.L., Cubed, M., Chesnutt, T.W., 2012. Evaluation of East Bay Municipal Utility District's Pilot of Watersmart Home Water Reports; A\&N Technical Services Inc.: Encinitas, CA, USA, 2013, pp. 1-78.

41. Nachreiner, M., Mack, B., Matthies, E., \& Tampe-Mai, K. (2015). An analysis of smart metering information systems: A psychological model of self-regulated behavioural change. Energy Research and Social Science, 9, 85-97.

42. Noël, Y., 1999. Recovering unimodal latent patterns of change by unfolding analysis: Application to smoking cessation. Psychological Methods, 4 (2), 173-191.

43. Nguyen, K. A., Stewart, R. A., \& Zhang, H. (2013). An intelligent pattern recognition model to automate the categorisation of residential water end-use events. Environmental Modelling and Software, 47, 108-127.

44. Novak, J., \& Schmidt, S. (2009). When Joy Matters: The Importance of Hedonic Stimulation in Collocated Collaboration with Large-Displays. In T. Gross, J. Gulliksen, P. Kotzé, L. Oestreicher, P. Palanque, R. Prates, \& M. Winckler (Eds.), Human-Computer Interaction - INTERACT 2009 (Vol. 5727, pp. 618-629). Springer Berlin Heidelberg.

45. Oinas-Kukkonen, H., 2013. A foundation for the study of behavior change support systems. Personal Ubiquitous Comput., 17 (6), 1223-1235.

46. Ouellette, J.A., Wood, W., 1998. Habit and intention in everyday life: the multiple processes by which past behavior predicts future behavior. Psychological bulletin, 124 (1), 54.

47. Prochaska, J.O., DiClemente, C.C., 1992. Stages of change in the modification of problem behaviors. Prog Behav Modif, 28, 183-218.

48. Prochaska, J. O., Butterworth, S., Redding, C. A., Burden, V., Perrin, N., Leo, M., Flahert-Robb, M. \& Prochaska, J. M. (2008). Initial efficacy of MI, TTM tailoring and HRI's with multiple behaviors for employee health promotion. Preventive Medicine, 46(3), p. 226-231.

49. Randolph, B., Troy, P., 2008. Attitudes to conservation and water consumption. Env sci. \& policy, 11 (5), $441-$ 455.

50. Reiss, S. (2000). Who am I?-The 16 basic desires that motivate our actions and determine our personality. New York: Tarcher/Putnam

51. Richter, G., Raban, D.R., Rafaeli, S., 2015. Studying gamification: the effect of rewards and incentives on motivation. In Gamification in education and business. Springer International Publishing, pp. 21-46.

52. Rizzoli, A.E., et al., 2014. The SmartH2O project and the role of social computing in promoting efficient residential water use: a first analysis. In Proc. of iEMSs 2014.

53. Russell, S., Fielding, K., 2010. Water demand management research: A psychological perspective. Water Resources Research, 46 (5), 1-12.

54. Ryan, R., \& Deci, E. (2000). Intrinsic and Extrinsic Motivations: Classic Definitions and New Directions. Contemporary Educational Psychology, 25(1), p. 54-67.

55. Schultz, P. W., Messina, A., Tronu, G., Limas, E. F., Gupta, R., \& Estrada, M. (2014). Personalized Normative Feedback and the Moderating Role of Personal Norms A Field Experiment to Reduce Residential Water Consumption. Environment and Behavior, 48(5), p. 686-710.

56. Schwarzer, R., Bäßler, J., Kwiatek, P., Schröder, K., and Zhang, J. X. (1997). The assessment of optimistic self-beliefs: Comparison of the german, spanish, and chinese versions of the general self-efficacy scale. Applied Psychology: An International Review, 46(1), p. 69-88.

57. Seyranian, V., Sinatra, G. M., \& Polikoff, M. S. (2015). Comparing communication strategies for reducing residential water consumption. Journal of Environmental Psychology, 41, 81-90. http://doi.org/10.1016/j.jenvp.2014.11.009 
58. Sintov, N.D., Orosz, M.D., Schultz, P.W., 2015. Personalized Energy Reduction Cyber-physical System (PERCS): A Gamified End-User Platform for Energy Efficiency and Demand Response. Proc of the DAPI 2015,, 602-613.

59. Skinner, B. F., 1957. The experimental analysis of behaviour. American Scientist, 45 (4), 343-371.

60. Steg, L., Vlek, C., 2009. Encouraging pro-environmental behaviour: An integrative review and research agenda. J. of Environmental Psychology, 29 (3), 309-317

61. Stewart, R. A., Willis R., Giurco, D., Panuwatwanich, K. and Capati, G. (2010). Web-based knowledge management system: linking smart metering to the future of urban water planning, Australian Planner, 47 (2), p. 66-74.

62. Terlet, J., Beach, T.H., Rezgui, Y., 2016. Smart Meters and In-Home Displays to Encourage Water Conservation through Behavioural Change. Int $\mathrm{J}$ of Social, Behavioral, Edu., Econ., Business and Ind. Eng., 10 (2), 520-526.

63. Van der Heijden, H. (2004). User Acceptance of Hedonic Information Systems. MIS Quarterly, 28(4), 695704.

64. Venkatesh, V., Morris, M., Davis, G., Davis, F., 2003. User Acceptance of Information Technology: Toward a Unified View. MIS Quarterly, 27 (3), 425-478.

65. WaterSMART. http://www.watersmart.com/. Last accessed on April $13^{\text {th }} 2016$

66. Willis, R. M., Stewart, R. A., Panuwatwanich, K., Jones, S., \& Kyriakides, A. (2010). Alarming visual display monitors affecting shower end use water and energy conservation in Australian residential households. Resources, Conservation and Recycling, 54(12), p. 1117-1127.

67. Tiefenbeck, V., 2014. Behavioral Interventions to Reduce Residential Energy and Water Consumption: Impact, Mechanisms, and Side Effects. Diss., Eidgenössische Technische Hochschule ETH Zürich, Nr. 22054.

68. Tiefenbeck, V., Goette, L., Degen, K., Tasic, V., Fleisch, E., Lalive, R., Staake, T., (2016). Overcoming Salience Bias: How Real-Time Feedback Fosters Resource Conservation. Management Science, Articles in Advance, pp. 1-19

69. Wang, Z., \& Capiluppi, A. (2015, September). A Social-Centred Gamification Approach to Improve Household Water Use Efficiency. In Games and Virtual Worlds for Serious Applications (VS-Games), 2015 7th International Conference on (pp. 1-4). IEEE.

70. Zhang, P. (2008). Technical opinion: Motivational affordances: reasons for ICT design and use. Communications of the ACM, 51(11), p. 145-147. 